\title{
B2C (BUSINESS-TO-CONSUMER) MOBILE MARKETING FOR CANADIAN
}

\section{APPAREL RETAILERS}

by

Leticia Ivonne Serna Zertuche

\section{B.A., Marketing}

Instituto Tecnológico y de Estudios Superiores de Monterrey, Mexico, 1996

\author{
A major research paper \\ presented to Ryerson University \\ in partial fulfillment of the \\ requirements for the degree of \\ Master of Arts \\ in the Program of \\ Fashion
}

Toronto, Ontario, Canada, 2013

(C) Leticia Ivonne Serna Zertuche 2013 


\section{AUTHOR'S DECLARATION}

I hereby declare that I am the sole author of this major research paper. This is a true copy of the major research paper, including any required final revisions, as accepted by my examiners.

I authorize Ryerson University to lend this major research paper to other institutions or individuals for the purpose of scholarly research.

I further authorize Ryerson University to reproduce this major research paper by photocopying or by other means, in total or in part, at the request of other institutions or individuals for the purpose of scholarly research.

I understand that my major research paper may be made electronically available to the public. 


\begin{abstract}
The mobile device industry has changed dramatically over the last 10 years. The world is swiftly adopting mobile devices, and Apple and Google have become major players in an industry that now encompasses a burgeoning mobile-fashion marketing business. This research project sought to help apparel retailers understand more about apparel consumers' usage of mobile devices and perceptions of mobile marketing strategies, and to shed light on better business practices. The study used a quantitative research method, along with cross-sectional, descriptive, and non-probabilistic sampling techniques. An online questionnaire survey was designed to collect data with a sample of 390 mobile device users in the Greater Toronto Area. SPSS was used for coding and analyzing the information.
\end{abstract}




\section{Acknowledgements}

First, I would like to express my deepest gratitude to my thesis supervisor Osmud Rahman; he has been a great mentor and a guide who helped me navigate through the labyrinth of academic research. His wisdom and vast experience paved the way. I thank him for his patience, support, encouragement, dedication, hard work, and positive attitude.

My sincere thanks to my second reader Grahame Lynch; his insights and feedback enriched this study.

I am extremely thankful to my loving husband, Rafael. His vision, emotional support, patience, hard work, goal-setting, and a long list of virtues have helped me on this journey. My gratitude to my family for their encouragement and support.

I would also like to thank Dr. Janna Eggebeen for her tremendous support while recruiting respondents, and for her efforts in the early stages of this study.

Lastly, a big thank you to all mobile users who participated in this study. 


\section{Dedication}

To Enriqueta, my loving grandma whose spirit is a daily inspiration. 


\section{Table of Contents}

\section{Page}

Author's Declaration.......................................................................................... ii

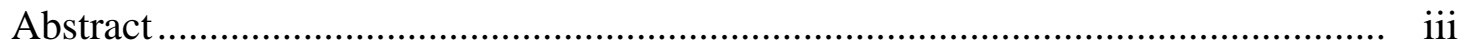

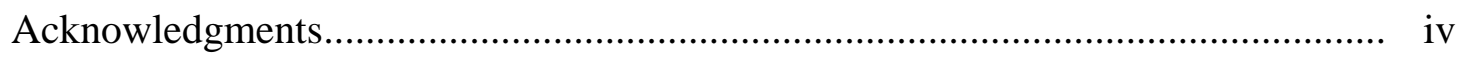

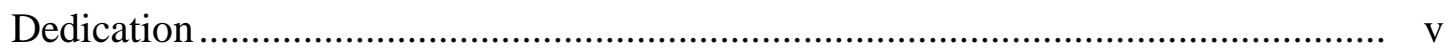

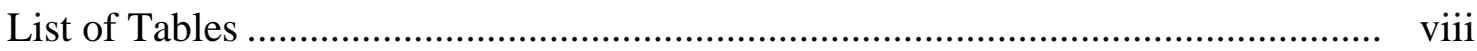

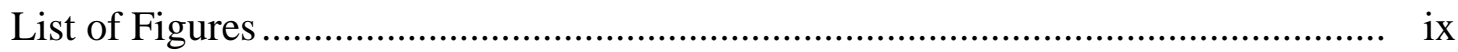

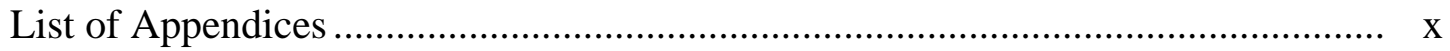

Chapter One: Introduction ..................................................................... 1

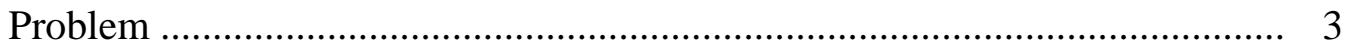

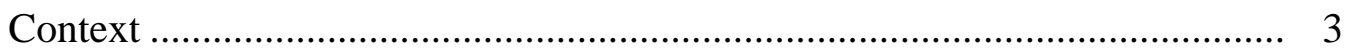

The Evolution of Wireless Networks Technologies.................................. 3

Wireless Local Area Networks (LANs): Wireless Fidelity (Wi-Fi) .............. 5

Bluetooth ............................................................................................... 7

The Evolution of Web Technologies.................................................... 8

Quick-Response (QR) Codes ............................................................ 10

Chapter Two: Literature Review ................................................................ 13

From Mail-Order Catalogue to Online Shopping....................................... 13

Mobile Commerce (M-Commerce) .......................................................... 14

Mobile Marketing as Part of a Multi-Channel Strategy ................................ 15

Digital Business Models..................................................................... 16

Location-Based Services and the In-Store Experience ............................. 16

Social Networking and Geo-Location ................................................ 18

Mobile Gaming................................................................................... 21

The Need for Customization ................................................................ 23

Chapter Three: Methodology and Procedures .................................................. 25

Data Collection ......................................................................................... 25

Information Analysis ................................................................ 27

Ethical Considerations ....................................................................... 27 
Chapter Four: Findings and Analysis ................................................................ 28

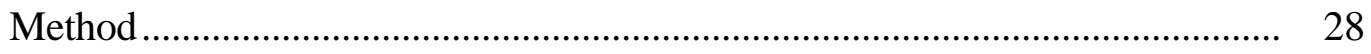

Sample

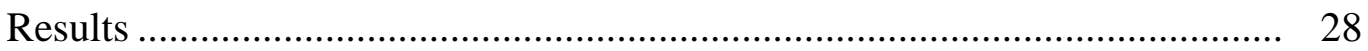

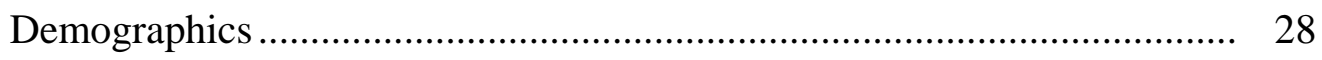

Most Popular Mobile Platforms................................................................. 29

Data Plans ……................................................................................ 32

Mobile Device Usage ...................................................................... 32

Quick-Response (QR) Code Application .................................................. 32

Shopping Channels ……………………………………...................... 34

Apparel Shopping — Significant Selection Criteria …………...................... 35

Apparel Information Sources.................................................................. 37

Mobile Communications .......................................................................... 40

Social Networking and Location-Based Services....................................... 41

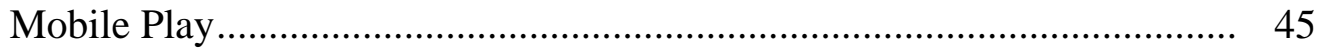

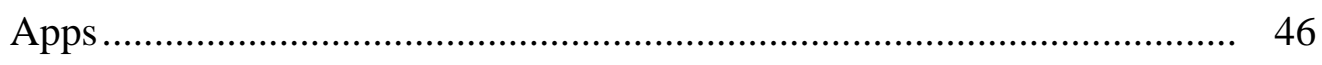

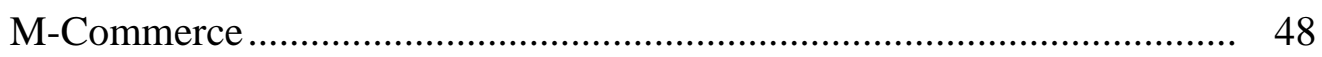

Chapter Five: Conclusions ............................................................................. 51

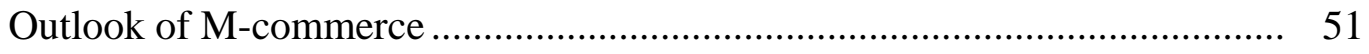

Mobile Communications ......................................................................... 51

Social Networking ................................................................................... 53

Apps and Mobile Gaming ……………………………………………... 54

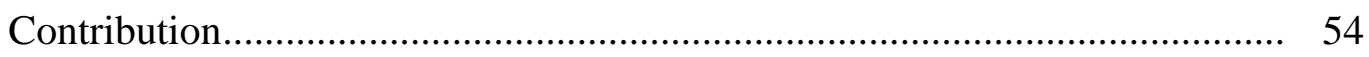

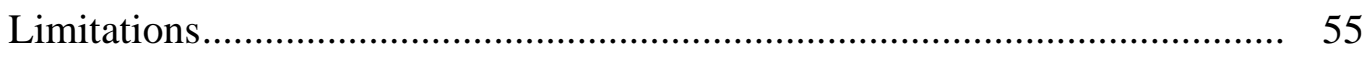

Future Research ............................................................................. 55

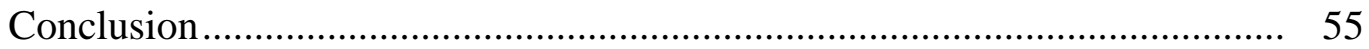

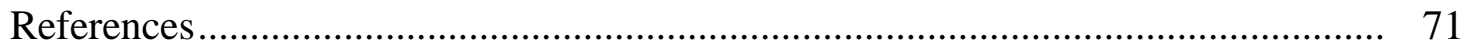




\section{List of Tables}

Table

Page

1: Demographic Profile of Study Sample ....................................................... 30

2: Cross-Tabulation of Age and Gender Among Respondents............................. 30

3: Mobile Devices Owned by Participants....................................................... 31

4: Usage of Mobile Devices_-Gender Differences .......................................... 33

5: QR Code Awareness .............................................................................. 33

6: QR Code Availability on Mobile Devices ...................................................... 34

7: Significance of Shopping Channel ............................................................. 35

8: Salient Apparel Selection Criteria ............................................................... 36

9: Significance of Apparel Information Source ............................................... 38

10: Major Determinants of the Factors Derived by Exploratory Factor Analysis .... 39

11: E-Mail Sign-Up From Apparel Retailers .................................................... 40

12: SMS (Text) Messages Sign-Up From Apparel Retailers................................. 41

13: Most Popular Social Networking Websites ................................................ 42

14: "Check-in" Awareness for Social Networking ............................................... 43

15: In-Store Apparel Decision-Making Preferences When Customers Need

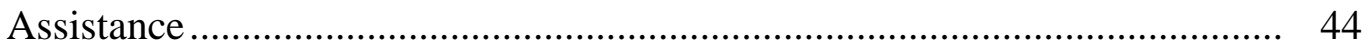

16: Usage of Mobile Device Camera for Apparel Decision Making...................... 44

17: Videogames/Online Games Participation ........................................................ 45

18: Games From Retailers Engagement ....................................................... 46

19: Level of Apparel Retailers’ Apps Engagement ......................................... 47

20: Potential App Features ......................................................................... 47

21: Mobile Payments Profile ................................................................................ 49

22: Use of Paypass Feature for Mobile Payments ............................................ 50 


\section{List of Figures}

Figure

Page

1: Apparel online shopping preferences by gender........................................ 36

2: Respondents' rationale for avoiding online apparel shopping ........................ 37

3: Scree plot with a clear inflection between the 1 st and 2 nd factors .................... 39 


\section{List of Appendices}

$\begin{array}{lll}\text { Appendix } & \text { Page }\end{array}$

A: Online Survey Consent Form................................................................... 57

B: Online Survey Questions .................................................................. 58

C: Public Posters With Request for Research Participation ................................ 69

D: Research Ethics Board Approval ............................................................ 70 


\section{Chapter One: Introduction}

Mobile marketing is defined as "the use of wireless media as an integrated content delivery and direct response vehicle within a cross-media or standalone marketing communications program" (Mobile Marketing Association, 2008, p. 22). Apple, once known as a computer company, is now the world's biggest music retailer and a leading phone maker. Results for the last quarter of 2012 show Apple sold 14 million iPads and 26.9 million iPhones (“Apple Reports Fourth Quarter Results," 2012). Amazon has also brought competition to the iPad with their Kindle Fire. Another competitor, Barnes \& Noble, has a variety of Nook tablets.

The use of mobile devices has been increasing. In early 2012 Google announced at the Mobile World Conference in Barcelona that the total number of Android activations had surpassed 300 million worldwide. They also reported to have 850,000 daily Android activations (Schmidt, 2012).

A smartphone is a phone that has an operating system that allows applications to be added or removed, that can take or send data, and can access web content (Krum, 2010). Users who own mobile devices are able to quickly conduct research on items, compare prices, read user-generated product reviews, locate the nearest retailers using the Global Positioning System (GPS) feature, share content through social networks, take notes, manage their calendars, check traffic conditions, check the weather forecast, translate foreign languages, take photographs and videos, scan QR codes, send and receive e-mail and text messages, speak with a virtual assistant (through voice recognition technology) like Sam from Android or Siri from iPhone, and of course, make phone calls. These changes are coming at a fast pace; they may even resemble the time when we first experienced the Internet which clearly revolutionized how the world communicates. With social networks also came a major change; people are now able to share 
content in real-time. It seems like an organic way to continue these efforts also from the academic perspective.

Cindy Krum (2010) explains this gradual mobile shift:

When text-based communication lost its ties to the traditional computer, it opened up a world of marketing opportunities, it provided recipients the opportunity to consume our message when it was convenient for them and to save it or carry it with them for future reference. (p. 11)

We are shifting into a mobile world, where the fixed telecom operators have been busy trying to meet a convergence point in which fixed and mobile worlds become part of the same telecom experience. Most of them are trying to avoid the substitution from fixed to mobile. In Austria, $20 \%$ of people do not have a fixed line. Internet giants such as Google, Amazon, and Microsoft are looking at mobile as a way to break out of the fixed Internet (Wisely, 2009).

David Wisely (2009) makes a comparison of mobile with Moore's law (Gordon Moore described trends in integrated circuits, he predicted that the period for doubling chip performance was eighteen months), about how long it takes for mobile efficiency to double, all other things being equal. He estimates that it is about 5 years; that is, "the capacity of $1 \mathrm{MHz}$ of spectrum doubles every five years and quadruples every ten years or one mobile generation" (p. 7). We have been witnesses of such rapid changes in capacity improvement and data rates. Mobile devices are becoming faster and more efficient, and the continuous trend in price reduction are all key factors in the quick adoption of this technology. According to Flurry Analytics, smartphones and tablets have become the fastest adopted technology in history; they were adopted faster than electricity, televisions, microwaves, personal computers, cell phones, and the Internet (as cited in Farago, 2012). 


\section{Problem}

Mobile marketing in apparel retail is still in its infancy. Further research is needed in order to help the industry take greater advantage of the benefits that this relatively new medium can provide. The purpose of this research study is threefold: (a) to gain a deeper understanding of the consumers' perceptions toward mobile marketing; (b) to explore and identify the potential of B2C (Business to Consumer) mobile marketing and (c) to obtain a clearer picture about the mix of mobile marketing strategies recommended for apparel retailers in order to raise brand awareness, enhance customer loyalty, and increase sales.

\section{Context}

This research will focus on smartphones and tablets, given their increased popularity among consumers which is reflected by solid sales from Apple's products (iPhone, iPad) and goods by manufacturers using Google's Android system that are now the strongest competitors to Apple. The scope of this study will be focused geographically in the Greater Toronto Area in Canada.

\section{The Evolution of Wireless Networks Technologies}

We could say that smartphones are the offspring of a marriage between a personal computer (PC) and a cell phone. After all, smartphones have processors just like computers (although less developed) and they have applications (or "apps," as they are colloquially called). The added advantage is that they also have touch screens, whereas we usually need to use a mouse on a regular PC to make our selections. To understand how this "marriage" occurred, a historical account of the evolution of network technologies will be presented.

Mobile operators such as Bell, Rogers, and Verizon use the radio spectrum to provide their services. The radio spectrum (which is usually auctioned by world governments) has been 
shared by a number of industries, including broadcasting, mobile communications and the military. During the 1970s, the introduction of cellular technology allowed for the division of geographical areas into cells, rather than frequencies, thus making a more efficient use of the spectrum (Mishra, 2010).

The first generation of cellular networks (1G) was introduced in the 1980s and was composed of analog signals for carrying voice (Ding, 2009). These early mobile phones lacked roaming and security, and had poor battery life (Wisely, 2009). Roaming is a service that allows users to operate in service areas other than the one from in which the user is originally subscribed. When a mobile device enters a city or geographic location other than its home service area, it is registered as a roamer in the new service area (Rappaport, 2002).

An important progress was made with second generation $(2 \mathrm{G})$ wireless networks because they became digital. Digital systems were superior in comparison with analogs due to several factors such as signal encryption, which provided privacy and security during transmission, better call quality with less interference, and roaming capabilities. Compression of digital data, which makes a more efficient use of the spectrum, subsequently allowed for an increased number of mobile phone users. During 2G, several data services were introduced such as Short Message Service (SMS) text messages. 2G networks were commercially launched on the Global System for Global communications (GSM) standard in Finland (Ding, 2009). GSM has dominated mobile communications worldwide. As of March 2008, there were over 3 billion GSM phones in use worldwide, representing about $85 \%$ of the total. It is also forecasted that GSM will not be switched off until 2018 at the earliest, in the UK alone (Wisely, 2009). 2G technologies are divided into Time Division Multiple Access (TDMA) and Code Division Multiple Access (CDMA) standards depending on their multiplexing (Ding, 2009). According to Cisco (n.d.), a 
multiplexer is "a type of hardware which can combine multiple communication channels into a single communications channel" (p. GL-8). The colloquially named "brick phones" with a large antenna were 2G. Subsequently, 2.5G came with the introduction of General Packet Radio Service (GPRS) which could provide data rates of up to $171.2 \mathrm{Kbps}$ (Rappaport, 2002) which could be used for services such as Wireless Application Protocol (WAP) access (WAP is a menu-based, condensed version of HTML specifically designed for mobile devices), SMS, Multimedia Messaging Service (MMS), and access to Internet and e-mails. GPRS networks later evolved into Enhanced Data rates for GSM Evolution (EDGE) which improved data transmission rates. EDGE was a part of the GSM system and it had three times the capacity (384 kbps) of GSM/GPRS networks. Internet, video and other multimedia were enhanced by achieving higher data speeds. One of the key factors for the success of GSM has been its ability to lower costs while increasing volumes, thus making the technology more affordable to a wider base of users (Wisely, 2009). The third generation of mobile networks (3G) offered improved system capacity, better spectral efficiency, and high speed packed data services ranging from 144 kbps to 2Mbps (Ding, 2009).

\section{Wireless Local Area Networks (LANs): Wireless Fidelity (Wi-Fi)}

Wireless LANs include all Wi-Fi networks; their terms are often used interchangeably. WLANs use Time Division Multiple Access (TDMA) to share access to the radio spectrum between different terminals; they use a license-exempt part in the spectrum for uplink and downlink transmissions. Wi-Fi hotspots provide wireless Internet access within public areas. They provide broadband or high speed mobile Internet access. Some of the current challenges that Wi-Fi presents are poor battery performance in Wi-Fi enabled handheld devices (with a 7 to 10 hours typical standby) and poor Quality of Service (QoS) (Wisely, 2009). For instance if a 
user is sitting at a local coffee shop, using it as a Wi-Fi hot spot, and is in the middle of an important online transaction, such as paying for an airline ticket, her/his transaction could get dropped if a large group of people arrive and start using the same Wi-Fi connection to download music or videos. This is the same reason why phone calls could get disconnected. Therefore Internet speed will depend on (a) the size and configuration of the hotspot, (b) the number of people using the network at the same time, and (c) the use that people give to the network such as checking emails and downloading video (Geier, 2007). Public Wi-Fi spots are commonly found in locations such as airports, restaurants, hotels, train stations, and conference halls. Shopping malls have also been slowly adopting this technology. Wireless routers are also available for households which enable a single DSL connection to a number of wireless and fixed PCs. Using this technology, users can be anywhere within their homes and still have an Internet connection with several different wireless devices such as smartphones, tablets, laptops, and portable gaming systems.

Transport companies such as airlines, trains, and buses have also been adopting WLAN technology to enhance their onboard entertainment offerings as well as to offer Internet access for their customers. Wi-Fi is limited to 10 to 50 meters around an access point, and many access points are needed for continuous coverage. Wi-Fi can reach very high speeds of five to $25 \mathrm{Mbit}$ per second for an isolated access point, however other users can drastically reduce this (Wisely, 2009). WLANs provide weak security and are only protected by a name and password, whereas cell phones provide a strong security through the use of Subscriber Identity Module (SIM) cards which make them almost impossible to gain unauthorized access. SIM cards contain the telephone number of the subscriber, encoded carrier identification details, the PIN number, and other user data (such as the phone book); they can be used from one phone to another and they 
connect the phone to the carrier and respective billing system. Solid walls and metal furnishings are a problem and may cause local shadowing or "dead spots" within the Wi-Fi hotspot. The $5 \mathrm{GHz}$ systems have the shortest range and fastest fall-off. In general, WLANs can reach about 30 meters indoors, but have a better coverage of 100 meters outdoors or more under ideal conditions.

\section{Bluetooth}

Bluetooth technology sends information within an individual's personal space, which is called Personal Area Network (PAN). Bluetooth was invented in 1994 by Ericsson engineers in Sweden (Bluetooth SIG Inc., 2012).

Wireless means a radio link, and radio links are subject to interference (Kammer, McNutt, Senese, \& Bray, 2002). Wireless can also mean “slower.” An Internet connection via a Bluetooth LAN has a maximum data rate of $723.2 \mathrm{Kbps}$ (Kammer et al., 2002). Therefore, wired high-speed connections are more suitable for large amounts of data. Bluetooth technology coverage can be divided in three classes for radio transmitters: Class 3 offers a range of coverage of one meter; Class 2 has a range of 10 meters; and Class 1 has a range of 100 meters. These figures are for typical use, however a flat land where there is not much interference can increase those levels. On the contrary, if the space is crowded, with many metal objects and a lot of people, the signal is blocked and absorbed, therefore propagation conditions are worse and ranges are reduced (Kammer et al., 2000). Bluetooth devices have a slight latency and therefore cannot connect instantly; it can take up to 10 seconds to establish a Bluetooth link. The Bluetooth system operates in the $2.4 \mathrm{GHz}$ band. This provides a license-free (in most parts of the world) worldwide potential. However other technologies that also use this band may cause interference, such as 802.11b, Home RF, Digital Enhanced Cordless Communications (DECT), 
and certain handheld short-range two-way radios (walkie-talkies). A variety of sources may interfere with Bluetooth links which include microwave ovens, thunderstorms, high-power sodium lights, and communications channels in other bands (such as GSM, CDMA). Signal fading problems can also be caused by distance or by actual blockers such as walls, furniture, and people. The more water content in the object, the more significant is the blocking effect (Kammer et al., 2000).

\section{The Evolution of Web Technologies}

Nova Spivack's Evolution of Web Technologies graph, as portrayed in Chaffey et al.'s (2009) Internet Marketing, helps to explain, from a technological point of view, where we are currently located. It shows that the PC era spanned from 1980 to 1990 . Personal computers (PCs) were commercially introduced, as was e-mail and FTP (File Transfer Protocol), with the desktop as structure. From 1990 to 2000 came the Web 1.0, the first public appearance of the World Wide Web along with the use of websites, databases, fileservers, SQL (Structured Query Language), MacOS (Macintosh Operating System), Windows, BBS (Bulletin Board System), and groupware. At this stage websites were static HTML (Hyper Text Markup Language) and provided marginal interaction with the user. After that, the web evolved into the concept of Web 2.0, a term coined by Tim O'Reilly (2004). The main change is that the web provided services that facilitated interaction of web users with sites to create user-generated content and encouraged behaviours such as community or social network participation, mashups (web applications that combine data and/or functionality from more than one source), content rating, use of widgets (badges or buttons incorporated into a site or social network space by its owner), and tagging (tracking of the origin or referring site or of visitors to a site and their spending patterns) (O’Reilly, 2005). At this point, Java (a programming language developed by Sun 
Microsystems that does not rely on an operating system and therefore can be used by multiple devices), XML (an advanced markup language that gives better control than HTML) and Flash, everything Google (Earth, Maps, Ads, Mail, Docs, etc.), wikis (websites that allow the creation and editing of any number of interlinked web pages), social networking (e.g., Facebook and Twitter), and keyword search and blogs (websites usually maintained by individuals with regular updated commentaries). Web 2.0 covered the period from 2000-2010. We are currently living in the Web 3.0 period that is forecasted to last from 2010 up until 2020, and we will find an increased use of semantic databases and searches (i.e., the development of artificial intelligence applications which recommend content and services to web users suggesting them the best products and brands). The purpose of the semantic web is that not only humans but also machines are able to understand and give meaning to the contents of documents (Berners-Lee, Hendler, \& Lassila, 2001). To fulfil this task, machine-readable descriptive labels and metadata are assigned to Internet content. Other trends that continue to expand are virtual worlds, the increased use of immersive virtual environments (e.g., Second life; streamed video (enabling to experience the media within a website before the whole clip is downloaded)) and syndication (content is distributed to third parties); personal data integration (i.e., increased exchange of data between social networks); and web application usage, sometimes also referred to as "cloud computing," where all that is needed for many activities is a computer with a web browser with local software applications used less widely (Chaffey et al., 2009). With this progressive use of "the cloud" (using multiple server computers via a digital network, as though they were one computer), it seems that the common PC is slowly disappearing. With the increasing use of mobile devices, this can become a reality. After all, we have been using cloud services for years; for instance, the web-based e-mail (from Yahoo, Hotmail, Gmail) has been widely accepted 
worldwide, and it is based in this cloud concept. Laptops nowadays seem bulky to carry around, compared to tablets and smartphones. We still currently use laptops, perhaps because of the software they contain; with cloud services this may not be necessary in the future. Wireless keyboards, such as those that use Bluetooth technology, enable tablets to bring a PC-like experience without the added bulk.

\section{Quick-Response (QR) Codes}

A Quick-Response (QR) Code or 2D (two dimensional) code is a type of twodimensional matrix symbology barcode that has position-detection patterns at three corners, arranged into adjacent square dots and spaces that contains embedded data; it is optical machinereadable (Kato, Keng, \& Chai, 2010). Smartphone users scan these codes using their camera, and this leads them to Uniform Resource Locator (URL) addresses which can link to a website, an online video, or an audio file, among other uses. Apparel retailers may use this technology within their stores to enhance the customer shopping experience. A QR code can be placed as a merchandise hangtag and customers can get further product information when they scan it. QR codes may also be placed in close proximity to merchandise, and when scanned, they can link to an online video (which could be setup in YouTube). This video may have promotional content, suggested product combinations (such as "this blouse goes well with this skirt") or instructions about product use (such as "how to tie a scarf" and "different ways a scarf can be worn"). QR codes may also link users to an audio file; such files may contain directions or guidance for shoppers.

Hansen \& GrØnbæk (2011) described the use of QR codes during the Aarhus city Festival in Denmark from 2007 to 2009. A 5-km route called "Red Route" was established and QR codes were placed along. An accompanying application named "UrbanWeb" relied on these 
visual tags to work as anchors to location based services and web content. Web pages provided information about concerts and events; other QR codes described specific location information from where the QR code or tag was scanned. Users were able to create (via comments) and share information about their experiences. App developers also experimented with user's-positionacquisition, wherever the tag was scanned as long as the user's smartphone was GPS-enabled. They also added a location-based poll service which allowed active user participation. Developers also built on the UrbanWeb framework an app called Mobile Urban Dramas which portrayed interactive audio plays that allowed participants to play the main character in a roleplay setting where the real city environment became the backdrop. Participants used their mobile phones, headsets, and maps to experience a "dramatic play" in the streets where they would trigger different scenes through audio, video, and text cues contained in QR codes. Likewise, apparel retailers may create a wide range of exciting experiences for customers through creative QR code use. At this point QR code adoption may still be at its infancy among apparel retailers. Retailers such as Columbia Sportswear and Timberland have used QR codes on their merchandise hangtags.

\section{Contribution}

Since the mobile marketing topic in apparel retail is relatively new, currently, the amount of literature is fairly limited. In the next section some of those earlier studies are presented. This proposed research intends to gather the puzzle pieces together, aiming to fill-in gaps of missing information. Some retailers (i.e., those specializing in selling electronics) are in a more mature phase of clients adopting m-commerce. Meanwhile, it could be said that industries such as fashion are still in a growing position in the cycle. Many of the pieces of this puzzle already exist; they are "out there," albeit fairly scattered. The intention of this research is to gather those 
existing mobile marketing components and to suggest possible recommendations for apparel retailers, which may enhance their digital strategy.

This study is divided in four phases: (a) research on existing theoretical framework and the general foundation structure; (b) data collection; (c) analysis, discussion, and delivery of results; and (d) conclusions. 


\section{Chapter Two:Literature Review}

\section{From Mail-Order Catalogue to Online Shopping}

In our history of retail shopping, consumers have shopped from mail-order catalogues, and some still do. Shim and Drake (1990) noted that consumers who have previous experience with mail-order shopping tend to have higher intention to purchase apparel items through mailorder than those who have no experience with mail shopping. Berkowitz, Walton, and Walker (1979) observed that telephone-order users tend to be mail-order shoppers as well. It seems that through past positive experiences, consumers are more willing to try new channels and products. Perhaps shopping convenience also plays a role; consumers who are primarily motivated by convenience were more likely to make purchases online, while those who value social interactions were found to be less interested (Swaminathan, Lepkowska-Wright, \& Lao, 1999). Kukar-Kinney, Ridgway, and Monroe (2009) suggested that the Internet is a favourite channel for the compulsive shopper, as consumers are able to buy unobserved, without other shoppers around, and therefore experience strong positive feelings during the purchase episode. The convenience of being able to shop using channels other than the regular bricks-and-mortar stores has provided alternatives for consumers. In the past, popular choices were placing phone orders and mail-order catalogue shopping; then there was a gradual shift to making online purchases using the Internet. Pookulangara, Hawley, and Xiao (2010) studied how attitudes and subjective norms predicted channel migration across the three channels (bricks-and-mortar stores, catalogues, and the Internet).They found that retailers need to pay more attention to the "social influence." They observed that consumers use aids such as blogs, customer-generated reviews, or e-word-of-mouth to make their shopping decisions. Shih (2004) used the Theory of Reasoned Action (TRA) model as well as Technology Acceptance Model (TAM) and found that the 
Perceived Ease of Use of Trading Online (PEOUT) significantly determined individual attitudes towards e-shopping. Another study that uses the TAM model found that shopping enjoyment and trust play significant roles in consumers adoption of e-shopping; customers are not only web users with trust/safety and information needs, but also shoppers with service and experiential needs (Ha \& Stoel, 2009).

\section{Mobile Commerce (M-Commerce)}

Currently we are experiencing the early beginning of another possible shift for online shopping - m-commerce (i.e., making purchases using mobile devices rather than PCs). Major apparel retailers such as The Gap and Macy's already offer the option for consumers to buy apparel merchandise online with websites developed specifically for mobile users. Jones and Vijayasarathy (1998) agreed that consumers had serious concerns about the security of Internet retailing, and expressed doubts about the legitimacy and longevity of some internet businesses. Cockburn and Wilson (1996) found that the lack of security sites and the absence of suitable online payment systems, coupled with slow connection times and limited Internet access by potential customers, were all impeding factors for the commercial development. Today connection times are certainly better than in 1996; however, interruptions of phone service and interference, the same that cause dropped calls, may lead to lost Internet connections. This, combined with poor signal strength, may have an impact on m-commerce sales. The lack of signal in certain places (e.g., the subway) may be another impediment.

According to Murthy (2004) a successful m-commerce transaction requires: (a) that the user is able to connect from different access points and that stays connected during movement; (b) a good bandwidth speed for fast and reliable communication; and (c) good battery power, 
with some provisions that in the case of disconnection, it does not affect the reliability of the whole transaction.

Back in the late 1990s, when Amazon first emerged, it offered a new e-commerce experience. Amazon's contribution to overall e-commerce has been astounding. The company first started selling books, which for potential customers may have seemed like a reasonably priced way of experimenting with online shopping. After past positive purchase experiences, customers gained confidence and they increasingly continued to shop with larger transaction amounts. In this case, for m-commerce to "take-off," the mobile world needs a retailer like Amazon that will offer good service, deliver the goods, and most importantly, that has the shopper's trust.

\section{Mobile Marketing as Part of a Multi-Channel Strategy}

Before smartphones became pervasive, most direct marketing was tied to a specific location. A marketer's ability to communicate with people largely depended on people actually being at specific places. Now in a world where most adults have cell-phones, we can more easily reach exactly who we are looking for, when we want to market them. This is because mobile phone numbers are assigned to "specific people instead of specific locations" (Krum, 2010, p. 11).

Mobile marketing efforts help to provide a seamless experience to the customer, going from the retailer's Internet website, to the mobile e-commerce (or m-commerce) website, to the bricks-and-mortar store (in-store experience). Rangaswamy and Van Bruggen (2005) explained that many retailers now explicitly offer a combination of physical stores, catalogues, call centres, and e-commerce sites. Offering more than one channel has become commonplace for many retailers. Hahn and Kim (2009) advocate for using the multi-channel approach; they studied the 
consumers' desire to use the Internet as a flexible tool for researching products and locating stores, as well as purchasing merchandise, and they also researched the effect of offline brand trust and perceived Internet confidence on online shopping intention within the multi-channel context. Weltevrenden and Boschma (2008) found that established high-street retailers that have ventured online tend to enjoy increased footfall, improved customer relationships, and enhanced promotional exposure. They also say that leading edge retailers that have developed the most sophisticated websites will most likely enjoy the greatest comparative advantage from their online ventures.

\section{Digital Business Models}

A fundamental aspect of the business model is whether the proposition appeals to consumers or businesses. Therefore, Internet marketing opportunities are described in terms of the extent to which an organization is transacting with consumers (business-to-consumer/B2C) or other businesses (business-to-business/B2B) (Chaffey et al., 2009). This research will be focused in $\mathrm{B} 2 \mathrm{C}$ transactions. The rationale is that smartphones and tablets are predominantly used by individuals rather than organizations. Companies such as Nokia are beginning to offer tablet services for businesses; however this is still in its infancy. When executives are using smartphones or tablets, they are usually using their personal devices, not company owned property (Martin, 2011).

\section{Location-Based Services and the In-Store Experience}

According to Junglas and Watson (2008), location-based services (LBS) are any service that takes into account the geographic location of an entity. Junglas and Watson note a distinction between location-tracking services and position-aware services. An example of location tracking services is the UPS tracking system (in which the system focuses on particular 
coordinates) whereas an example of location-aware services may be the ads sent to consumers' mobile phones when the user is in close proximity. The advantage of location-aware services is that they also take into account the coordinate's surrounding context. Context can be any source of useful information for the intended application; it can take the form of the user's identity, location/position, time, orientation of movement, navigation history (history of a user's position), purpose of use, social and cultural situation, physical surroundings, and system properties. Therefore more relevant messaging and services can be sent to a user if the information received from them is adjusted to their context (Mohammadi, 2011).

There are outdoor and indoor positioning technologies. The outdoor technologies can be divided in satellite-based positioning (GPS) and network-based positioning, which are based on triangulations and trilaterations to identify the mobile device's position in relation to radio base stations. Indoor positioning systems (IPS) provide location estimation for wireless devices inside buildings and closed environments such as stores, hospitals, warehouses, hotels, and airports (Mohammadi, 2011). These systems are usually based on RFID (Active Radio Frequency Identification).

Bricks-and-mortar stores can set up location-based services (LBS), with RFID technologies that broadcast digital messages to enabled devices within a specific radius or proximity. These broadcasts send marketing messages directly to the consumer when they are in the area. The most suitable technologies for this purpose are Bluetooth and Wi-Fi (Wireless Fidelity).They have the advantages of reaching the client who is already there, thus adding excitement. They may also increase impulse buying and, ideally, enhance brand perception with the client. These broadcasts reach enabled mobile devices such as mobile phones, laptops, and tablets within the covered radius. An important aspect is that the mobile devices must be enabled 
in order to receive these messages. This can easily be communicated to clients with in-store posters encouraging them to enable their devices to download promotional information. Sales associates can also act as promoters and offer clients guidance on how to enable their devices (Krum, 2010). Another way of reaching shoppers is through the use of applications (apps). Retailers and shopping malls may develop their own apps which can be programmed to send messages, and enable the GPS tracking locator, which could entice a shopper in location A to visit nearby retailer B and receive an instant discount or another appealing promotion.

Permission for this information exchange is inherently granted when the user agrees to the terms and conditions of use when downloading and installing the app.

\section{Social Networking and Geo-Location}

The geographic location of a mobile device user is increasingly a topic of interest to marketers. Facebook is the most widely used social network; its membership base reached over one billion users in October 2012 (Smith, Seagall, \& Cowley, 2012). With social networks people are now able to share content in real-time and from any place (as long as they have an Internet connection). Half of Facebook's members use it from mobile devices and 102 million of them access it exclusively through their mobile devices (rather than from their PCs). Building a better mobile experience is one of Facebook's top priorities, as Mark Zuckerberg its founder and CEO said in a recent interview "That's the future" (as cited in Smith et al., 2012, para. 12).

Foursquare was launched in March 2009 and it added a new layer to social networking, recording the time and whereabouts of users through using the app on their mobile devices. Foursquare is a platform in which users can digitally detect which businesses (restaurants, entertainment, shopping, etc.) and attractions are nearby. Facebook launched its own version of this and calls it Places. This feature enables users to share their location with "Facebook friends" 
in real time and view friends' comments about past visited places. These are examples of Augmented Reality (AR) in use. AR, according to Skeldon (2011), is the "overlaying of digital information onto the real world" (p. 100). The term was coined by Tom Caudell, a scientist at Boeing. In 1996 he used it to describe the company's wiring helmet. Now it contains computergenerated content, which normally include graphics and audio. It uses "superimposed over live images to enhance the real environment around us" (Skeldon, 2011, p. 99). For instance, geolocation app users can use a map of their location and look for nearby merchants. They can find information such as store hours, their phone, a description of the retailer, and they can see comments or suggestions that other users have left digitally. Therefore users are able to "augment their reality" by having extra information about a specific retailer. This should be of particular interest to merchants, because potential clients may base their opinions from such postings, either in a positive or in a negative way. Other functionality of geo-social networking is the ability to "check-in" to a place, which would mean to register with the app and record the place and time of their visit. Sometimes businesses will offer incentives to lure customers into their stores and the client can "unlock" a reward, or get a special promotion or discount on products and services. This information can be linked with other social media applications (such as Pinterest and Instagram), allowing for a much larger audience. Among other uses, Foursquare has also become a digital city guide fed by the thousands of comments of its users. Geodemographic values can be used to predict the general interests of a user. During the lifetime of a user, the frequencies of how often the user visits particular businesses or types of businesses that offer particular products or services, can be recorded. Furthermore, periodical patterns can also be easily detected in the sequence of visits (Gidofalvi \& Larsen 2008). 
Fayyad, Piatetsky-Shapiro, and Smyth (1996) describe Data Mining (DM) or knowledge discovery in databases, as "the extraction of interesting, meaningful, implicit, previously unknown, valid and actionable information from a pool of data sources". This information can be used for executive decision making. We are witnessing the start of deeper and more meaningful consumer relationships that only mobile devices are making possible.

Nayak and Seow (2004) discuss the advantages of geo-location information through Data Mining. With that information over time patterns may emerge and "knowing the locations that a person frequents will allow the prediction of a user's daily life" (p. 117). Therefore we can target customized marketing campaigns while segmenting groups; for instance, we can identify housewives who frequent retail stores and go shopping for groceries often. Perhaps we can also learn about students who frequent universities, concerts, and pubs. With Associative Data Mining a retailer may also be able to predict which stores a person will most likely visit. Therefore, if a customer is at a place A, nearby retailers can suggest a trip to their store in location B, based on experience with previous visitors (Nayak \& Seow, 2004). Retailers could entice customers to come and visit their stores possibly with discounts sent directly to the customers' smartphones at the right time, because it already is the right place. However, to take full advantage of this feature, retailers need to make sure that a wireless network signal exists within that space, particularly if the venue is at a mall indoors. Otherwise retailers may wish to have Wi-Fi available so the customers' phones are ready to receive retailers' communications. According to Varshney (2001), in terms of B2C, "providing all information to every user, ignoring the user's interest in the type of information given, can result in the user unsubscribing to the services offered by the business" (p. 1). Adding to Varshney's concept, retailers should also consider the frequency of such communications. Because, even if consumers are interested 
in receiving those communications, for instance, e-mails, they can also feel annoyed if they receive too many messages. The customesr can end up marking the sender as a spammer and not read anything at all; or they can unsubscribe and opt out from receiving further e-mails.

\section{Mobile Gaming}

We have come a long way since Tetris, and the Snake game in Nokia's phone back in 1997. At that time, mobile phone manufacturers, such as hegemonic Nokia, had proprietary rights over the games they shipped the devices with. In 2007 with the introduction of the iPhone, Apple took the carrier out of the content-creation equation. This allowed developers to create content (such as mobile games), upload it to the AppStore, and sell in a global scale (Chasey, 2010). In the U.K., carriers like T-Mobile offered games supported on advertising. Also around 2007 and 2008, gaming companies began to distribute games to mobile gamers on Facebook. The Sims game provided additional downloadable content for mobile devices. Several gaming companies focused exclusively on mobile devices rather than regular PC gaming or consoles (Feijoo, Gómez-Barraso, Aguado, \& Ramos, 2012). Apple is also becoming a dominant player in the gaming industry, having sold over 500 million iOS devices that have generated over 40 billion downloads (from over 800,000 apps) — and a sizable amount of those apps are games. In comparison, Microsoft has sold 75 million Xbox consoles worldwide (since their launch, 7 years ago), Nintendo has sold 100 million Wii consoles and 150 million Nintendo DS (including all versions) (Siegler, 2013). Clearly, Apple is going at a faster pace.

Gaming companies, just like other content-generating apps, have developed different mobile business models; they have the "freemium" model, that is, offering versions of the game (or app) free of charge, but charging a premium for advanced functionalities, levels, features, or virtual goods (such as virtual weaponry, virtual pets, lives, levels, avatar accessories, special 
outfits, money, etc). These models sometimes also rely on advertising (advergaming).

Advertising to online players may have tracking advantages from Internet-based advertising. According to the Office of the Privacy Commissioner of Canada (2011), "behavioural advertising involves tracking consumers online over time, in order to deliver advertisements that are targeted to their inferred interests" (para. 2). Yang and Wang (2008) studied the advertising effectiveness of virtual product placement in online games and found that the right combination of product type and placement form can prove to be an effective marketing strategy.

"Pay as you go" models have an upfront cost per game or app download. Subscriptionbased models work by charging clients fees for membership and online gaming (an example is Xbox Live Gold, which has added online gaming features for its customers). Popular massive multiplayer online role-playing games (MMORPGs) such as World of Warcraft (WoW) also rely on monthly subscriptions (\$15 dollars as of this writing), as well as selling virtual goods which, for example, can cost $\$ 1, \$ 5$ and $\$ 10$ dollars (E. Montemayor, personal communication, February 18, 2013). They also entice their customers to "Recruit-a-Friend," gaining free subscription time for themselves as well as online virtual goods. WoW reached over 10 million subscribers worldwide with their most recent expansion "The Mists of Pandaria” (Karmali, 2012).

According to Çeltek (2010) advergaming is the "inclusion of brands in electronic games or the brand as the game" (p. 267). Advergames can be a tool for marketers to enhance brand loyalty, and also provides the possibility of collecting data from clients that may benefit CRM efforts. Gaming can be used to drive brand awareness, educate shoppers about product features, and support marketing efforts. For example, gamers can be asked to enter promo codes from their previous purchases to unlock extra gaming features. Successful gaming is usually addictive 
and entertaining. Zynga became extremely popular among Facebook users. In 2010 Facebook had more than 120 million users playing Zynga's online games (MacMillan, 2010). The company was able to capture a market of non-gamers - for instance stay-at-home-moms who would otherwise never play in regular consoles became casual gamers. The games were easy to play and had hints attached educating players along the way. For Zynga, the viral effect was and still is of great relevance. For this purpose, Zynga games entice players to ask their friends to join them, by giving them extra rewards or features once they add new gamers. In Farmville, the most popular game from Zynga, players asked their friends to become "their neighbors"; in Candy Crush Saga, friends "give lives" to friends who need them. This stratagem makes the game go viral. The goal is to engage many people in a short time, making them as addicted as possible to the game.

Lee and Radosevich (2012) compared the differences between paid apps versus free apps. They found that free apps formed larger audiences faster compared with paid apps. They also found that selling items within apps ("in-app purchasing") benefited free apps to improve their ranking within app stores. Frequent upgrades and the re-introduction of apps helped in obtaining higher rankings, and thus increased visibility in app stores, enhancing advertising revenue opportunities.

\section{The Need for Customization}

Peppers and Rogers (1993) predicted a more proactive role for the Internet in which it enabled "one-to-one marketing." Hoffman and Novak (1997) suggested that the Internet facilitated communication with customers through individualized marketing rather than mass marketing. Luedi (1997) created a model for internet one-to-one communications: the personalization of web-page content. Currently we can see this level of personal customization 
with Amazon, which takes into account shoppers browsing behaviour and past purchases to deliver a personalized web page with product suggestions. Another similar model was created by Gillenson, Sherell, and Chen (1999) for the customization of e-mail. Kaufman-Scarborough, Morrin, and Bradlow (2010) suggest that in the future, the wealth of consumer-oriented data will also allow retailers to better predict their customers' requirements and, therefore, provide a better level of customer service. Wirtz, Schilke, and Ullrich (2010), while developing strategic business models, note that retailers will face increasingly intense pressure from consumers to deliver a more authentic dialogue, provide opportunities to customize the interface, and allow consumers to generate their own content. Arora et al. (2008) found that effective one-to-one marketing requires the capture of significant quantities of customer-oriented information, so that their needs and preferences can be inferred, and then, elements of the marketing mix can be specifically tailored to these requirements. A loyalty program (LP) is a "marketing process that generates rewards to customers based on their repeat purchasing" (Kumar \& Reinartz, 2006, p. 163). LPs may become important tools to identify, award, and retain valuable customers; with the aid of data mining, customized promotions and recommendations can be generated for loyalty program members.

Mobile mediums help us to expand the apparel retailer's existing customer databases with deeper consumer knowledge (lifestyle, product preferences, historical information on past purchases, demographics, etc.). We can even know consumers' whereabouts through the GPS feature, how often (and at what time) they visit retail locations, and if they are leaving customers' reviews online. 


\section{Chapter Three: Methodology and Methods}

\section{Data Collection}

This study uses descriptive research, which, as Churchill (1995) and McDaniel \& Gates (1999) explained, attempts to describe characteristics of certain groups; estimates proportion of people in a population who behave in a certain way; and makes specific predictions. A selfadministered online survey was the measurement instrument of choice; the rationale was that the online questionnaire offered more flexibility to respondents, giving them the freedom to answer it anonymously at their convenience. Online surveys offer a number of advantages over paper surveys including lower financial costs, reduced coding time, fewer coding errors, and more convenience for the participants (Kang \& Park-Poaps, 2010).

The survey consisted of 49 closed- and open-ended questions, including Likert scale and nominal and ordinal questions (see Appendix B). The website was configured in a way that would take respondents to different subsequent questions depending on their responses. For instance, the subsequent question for "Have you ever purchased something with your smartphone or tablet?" was "If you haven't made purchases with your mobile device, what are the reasons?" if the respondent's answer was "No." Therefore if someone provided a different answer, the system would simply skip this question (thus, though Appendix B shows the complete questionnaire, respondents may not have been asked the same questions). The flow of the survey and the type of questions that appeared on respondents' screens depended directly on their previous answer choices. Participants were able to access the online survey through personal computers and also through mobile devices such as smartphones and tablets.

Adult males and females (18 years or older) were recruited for the study in the Greater Toronto Area. Subjects were required to be computer/Internet-literate and needed to own a 
smartphone or tablet to be eligible to participate. Toronto was chosen for two reasons: (a) it is a cosmopolitan city that offers an important cultural convergence point; and (b) the population of mobile users is relatively high as compared to other cities in Canada. The age rationale was to observe the generational differences in behaviour towards the use of mobile devices.

A sample size of 461 respondents was obtained. Malhotra (2007) suggests that a sample size between 300 to 500 surveys is the typical range suggested for a test marketing study. This research was cross-sectional, gathering a snapshot of the variables of interest at a single point in time. The sampling techniques used were non-probabilistic, which relied on the personal judgment of the researcher rather than chance. Convenience sampling and judgment sampling were used. Questions included attributes such as perceptions towards online apparel purchase decisions (e.g., "Do you shop online for apparel?"; upon receiving a negative reply, the survey then asked: "What are the reasons you do not shop for apparel online?"). The role of mobile social media for apparel purchase decisions was also explored, as was respondents' perceptions about location-based services and permission-based email subscriptions, as well as their attitudes towards m-commerce. Demographic data was also collected for classification purposes. In several of the close-ended questions, the choice of "Other" was added at the end in order to learn more about unforeseen possible responses.

Prior to data collection, 10 pre-tests were administered to assess the applicability and efficacy of the measuring instrument. Based on the results and observations of the pre-test, minor revisions were made to improve clarity and to add extra choices to the close-ended questions. The average time that it took respondents to complete the survey was also observed and taken into account for recruitment purposes. The time varied in average from 10 to 20 minutes 
depending on respondents' choice of answers made and also on their individual speed for providing such answers.

Requests for participants were made on social networking sites within Ryerson University, as well as email requests through administrative members. Several faculty members also facilitated invitation distribution by posting the online survey link for their students on electronic boards. Letter-sized posters were placed throughout the different faculties and schools within Ryerson University, and also at public venues nearby such as retail stores. All due permissions were obtained prior to placing the posters in public facilities.

\section{Information Analysis}

All response data were entered and coded into Statistical Package for the Social Sciences (SPSS) version 20.0 statistical software for its analysis. Questions that were determined as not fit or no longer relevant to the findings of this study have been discarded.

\section{Ethical Considerations}

This research was conducted using questionnaires, therefore human participation was needed. An approval from Ryerson's Research Ethics Board (REB) was sought for this purpose. The ethics protocol for approval prior to commencement of study was sent to the REB. The age range of participants was from 18 to more than 55 years old. The age groups were divided into five categories: 18 to 24,25 to 34,35 to 44,45 to 54 , and 55 and older. The rational was to observe the generational differences in behaviour towards the use of mobile devices.

When accessing the online survey the researcher provided clear written statements as to what individuals were agreeing to when deciding to participate in this study. Respondents were asked to acknowledge and agree to the consent agreement on the first page of the online survey. Privacy and consent statements were also included in the posters placed in public places. 


\section{Chapter Four: Findings and Analysis}

\section{Method}

A self-administered online survey was distributed in Toronto among adult Canadians who owned a smartphone and/or a tablet. The objective of this study was to shed light on consumers' perceptions and behaviour toward mobile devices and their role in mobile marketing for apparel purchase decisions.

\section{Sample}

A total of 390 respondents took part in this study. The website that contained the selfadministered survey was configured in a way that respondents would be taken to different subsequent questions depending on their answers. Therefore there is a variation in the amount of received answers per question. Not every respondent answered all the questions, either because they were not applicable to them or simply because they chose not to answer them.

Demographic questions such as gender, age, household income, and ethnicity were placed at the end of the survey. This placement has been supported in the literature (e.g., Dillman, 2007; Fink, Bourque, \& Fielder, 2003; Jackson, 2009; Stoutenbourgh, 2008; Whitley, 1996). The rationale was to build rapport with participants and to engage respondents with "interesting" survey questions to be answered before "boring" demographic questions, and to prevent attritions by placing potentially "anxiety inducing" questions at the end, such as household income.

\section{Results}

Demographics. A significant majority (69\%) of the respondents was female ( $n=269)$. Of these, 157 respondents $(40.2 \%)$ fell into the segment ranging from 18 to 24 years of age $(n=28$ male; $n=129$ female), and 95 respondents belonged to the segment of ages 35 to 44 years ( $n=35$ male, $n=60$ female) as indicated in Tables 1 and 2 . A considerable number of participants 
$(\mathrm{n}=116,29.7 \%)$ had annual household incomes of less than $\$ 30,000$ dollars, this may be explained by a significant number of students who were invited to fill out the survey. The three most predominant ethnic groups were White/Caucasian $(n=155,39.7 \%)$, Hispanic/Latin $(n=113$, 29\%), and Asian/Oriental ( $\mathrm{n}=76,19.5 \%)$.

Most popular mobile platforms. Apple has a hegemonic presence among respondents: $45.9 \%$ of them own an iPhone, followed by a $26.1 \%$ who have a BlackBerry, and in third place among popular smartphone platforms is Google's Android with 20.9\% (see Table 3). Apple is also the leader in the tablet market with $26.1 \%$ of ownership for the iPad. This finding is consistent with a recent report from IBM (2012) which notes that the iPad generated more traffic than any other tablet or smartphone, getting as much as $10 \%$ of the online shopping channel. The iPad also dominated tablet traffic at $88.3 \%$, followed by Nook from Barnes \& Noble at $3.1 \%$, Amazon’s Kindle at 2.4\%, and Samsung's Galaxy Android at 1.8\% (IBM, 2012). This information also matches this study's findings, where the use of other tablet platforms besides the iPad (e.g., Android, Nook Color, Amazon's Kindle Fire, and BlackBerry’s Playbook) is fragmented, and they are not widely owned by mobile users at the present time. Future research is needed to investigate the potential of other platforms, including Microsoft's newly released Surface tablet.

The total percentage does not add to $100 \%$ because respondents may own more than one mobile device. These results are meaningful because executive decision makers can plan web and app development that focuses on retailers' resources in the most popular mobile platforms.

Seventy-three percent of respondents own one smartphone $(n=390), 14.9 \%$ own two smartphones, and 3.1\% reported owning three or more smartphones. Forty-five percent of respondents own tablets; from those, $82.4 \%$ reported that they own one tablet or e-reader device, $15.3 \%$ own two tablet devices, and $2.3 \%$ own three or more of those devices. 
Table 1

Demographic Profile of Study Sample $(N=390)$

\begin{tabular}{|l|c|c|}
\hline Gender & $\mathrm{n}$ & $\%$ \\
\hline Male & 121 & 31.0 \\
\hline Female & 269 & 69.0 \\
\hline Age & & \\
\hline $18-24$ & 157 & 40.3 \\
\hline $25-34$ & 91 & 23.3 \\
\hline $35-44$ & 95 & 24.4 \\
\hline $45-54$ & 30 & 7.7 \\
\hline 55 and up & 17 & 4.4 \\
\hline Household Income & & \\
\hline Less than 30,000 & 116 & 29.7 \\
\hline $30,000-60,000$ & 70 & 17.9 \\
\hline $60,000-90,000$ & 47 & 12.1 \\
\hline $90,000-120,000$ & 25 & 6.4 \\
\hline $120,000-150,000$ & 22 & 5.6 \\
\hline 150,000 or above & 32 & 8.2 \\
\hline Prefers not to answer & 78 & 20.0 \\
\hline Ethnic Background & & \\
\hline White/ Caucasian & 155 & 39.7 \\
\hline Hispanic/ Latin & 113 & 29.0 \\
\hline Asian/ Oriental & 76 & 19.5 \\
\hline $\begin{array}{l}\text { Other (Black, Arab, } \\
\text { Indian, mixed-race) }\end{array}$ & 46 & 11.8 \\
\hline
\end{tabular}

Table 2

Cross-Tabulation of Age and Gender Among Respondents $(N=390)$

\begin{tabular}{|l|c|c|c|c|c|c|c|c|c|c|c|}
\cline { 2 - 13 } \multicolumn{1}{c|}{} & \multicolumn{10}{c|}{ Age } \\
\cline { 2 - 13 } \multicolumn{1}{c|}{$18-24$} & \multicolumn{2}{c|}{$25-34$} & \multicolumn{2}{|c|}{$35-44$} & \multicolumn{2}{c|}{$45-54$} & \multicolumn{2}{c|}{55 and up } & Total \\
\hline Gender & Frequency & $\%$ & Freq. & $\%$ & Freq. & $\%$ & Freq. & $\%$ & Freq. & $\%$ & Frequency \\
\hline Female & 129 & 82.2 & 57 & 62.6 & 60 & 63.2 & 14 & 46.7 & 9 & 52.9 & 269 \\
\hline Male & 28 & 17.8 & 34 & 37.4 & 35 & 36.8 & 16 & 53.3 & 8 & 47.1 & 121 \\
\hline Total & 157 & 100.0 & 91 & 100.0 & 95 & 100.0 & 30 & 100.0 & 17 & 100.0 & 390 \\
\hline
\end{tabular}


Table 3

Mobile Devices Owned by Participants

\begin{tabular}{|l|c|c|}
\hline Mobile Device & $\mathrm{n}$ & $\%$ \\
\hline iPhone & 179 & 45.9 \\
\hline iPad & 101 & 25.9 \\
\hline Blackberry & 104 & 26.7 \\
\hline Google Android & 85 & 21.8 \\
\hline Regular cell-phone & 35 & 9.0 \\
\hline Amazon Kindle & 18 & 4.6 \\
\hline Android Tablet & 16 & 4.1 \\
\hline Kobo & 11 & 2.8 \\
\hline Nokia Symbian phone & 13 & 3.3 \\
\hline Blackberry's Playbook tablet & 12 & 3.1 \\
\hline Nokia Windows phone & 5 & 1.3 \\
\hline Nook or Nook Color & 4 & 1.0 \\
\hline Sony e-Reader & 4 & 1.0 \\
\hline Other (iPod touch) & 6 & 1.5 \\
\hline Kindle Fire & 3 & 0.8 \\
\hline
\end{tabular}

Participants answered an open question about mobile device ownership; here are the most interesting answers derived from content analysis: "[I have] 3 months with my iPhone, 2 years with my Kindle. Previously I had a BlackBerry Curve for 3 years but only used it for email and phone calls." Another respondent mentioned: "I originally had a BlackBerry but upgraded to an Android this past summer so I've had it for 4 months now." It seems that platform migration may be perceived as an "upgrade." Some other respondents reported changing platforms: "I've been using my iPhone for about a year but I had a BlackBerry for about 3 years before that"; "6 months with iPhone, 2 years prior with BlackBerry Curve.” Other respondents maintain brand loyalty: "10 years with my BlackBerry, 2 years with my Playbook"; "4 years with BlackBerries"; “5 years iPhone, 2 years iPad.” Several other respondents own multiple platforms, such as Android phones and iPads, or BlackBerries and iPhones. 
Data plans. A data plan gives users access to the Internet wherever their mobile provider has coverage. In total, $74.1 \%(n=321)$ of the respondents subscribed to a data plan and $14.5 \%$ $(n=63)$ reported that they only accessed the Internet through Wi-Fi; $11.3 \%(n=49)$ of participants did not currently subscribe to a data plan. There are devices such as the iPod touch that do not require a data plan to function. For this reason they are popular among teenagers (and their parents who save on monthly phone bills) because they can access the Internet through Wi-Fi and download songs, videos, send text messages, and use phone services such as Skype. They can do virtually the same things as smartphones, minus the telecom carrier relationship.

Mobile device usage. As indicated in Table 4, most of the respondents used their mobile devices for phone calls. However, female respondents tended to use their devices more frequently for SMS text messaging $(n=234)$ and for taking photographs $(n=221)$ than their male counterparts. On the other hand, males liked to use their devices for checking e-mails $(n=103)$ and Internet browsing ( $\mathrm{n}=98)$. In the "Other" category for mobile usage, participants responded: art \& design, stock watch, note taking, calculator, calendar/organizer, audio-books, and alarm clock/timer.

Quick-Response (QR) code application. Almost 70\% of respondents indicated that they were familiar with QR codes (see Table 5) and 42\% of respondents had downloaded a QR code app (scanner or reader application) on their mobile device (see Table 6). Only 39\% did not have a QR code app on their mobile device and 19\% were not sure if they had a QR code app installed. The youngest group of 18 to 24 has the highest level of awareness about QR codes with $77 \%$. 
Table 4

Usage of Mobile Devices-Gender Differences

\begin{tabular}{|l|c|c|c|c|c|c|c|}
\hline & \multicolumn{2}{|c|}{ Female } & \multicolumn{3}{c|}{ Male } & & \\
\hline Mobile Activity & Frequency & Percentage & Top 10 & Frequency & Percentage & Top 10 & $\mathrm{n}$ \\
\hline Phone calls & 253 & 70.28 & 1 & 107 & 29.72 & 1 & 360 \\
\hline Text messaging (SMS) & 234 & 71.34 & 2 & 94 & 28.66 & 4 & 328 \\
\hline E-mail & 215 & 67.61 & 4 & 103 & 32.39 & 2 & 318 \\
\hline Browse the Internet & 209 & 68.08 & 5 & 98 & 31.92 & 3 & 307 \\
\hline Take photos/sharing them & 221 & 72.46 & 3 & 84 & 27.54 & 7 & 305 \\
\hline Social Media & 208 & 70.51 & 6 & 87 & 29.49 & 6 & 295 \\
\hline Maps/Directions (GPS) & 178 & 66.92 & 7 & 88 & 33.08 & 5 & 266 \\
\hline Listen to music & 167 & 70.46 & 8 & 70 & 29.54 & 10 & 237 \\
\hline Use apps & 155 & 67.4 & 9 & 75 & 32.6 & 9 & 230 \\
\hline News/weather/traffic/sports & 153 & 66.52 & 10 & 77 & 33.48 & 8 & 230 \\
\hline Watch videos & 132 & 66 & & 68 & 34 & & 200 \\
\hline Play games & 137 & 69.54 & & 60 & 30.46 & & 197 \\
\hline Read a book & 78 & 63.41 & & 45 & 36.59 & & 123 \\
\hline Read blogs & 78 & 67.24 & & 38 & 32.76 & & 116 \\
\hline Translator & 49 & 62.03 & & 30 & 37.97 & & 79 \\
\hline Compare items/prices & 44 & 61.97 & & 27 & 38.03 & & 71 \\
\hline Scan QR code/barcodes & 39 & 60 & & 26 & 40 & & 65 \\
\hline Other & 8 & 72.73 & & 3 & 27.27 & & 11 \\
\hline
\end{tabular}

Table 5

QR Code Awareness

\begin{tabular}{|c|c|c|c|c|c|c|c|c|c|c|c|c|}
\hline \multirow[b]{4}{*}{ Answer } & \multicolumn{12}{|c|}{ Are you familiar with QR codes? $\mathrm{N}=388$} \\
\hline & \multicolumn{12}{|c|}{ Age } \\
\hline & \multicolumn{2}{|c|}{$18-24$} & \multicolumn{2}{|c|}{$25-34$} & \multicolumn{2}{|c|}{$35-44$} & \multicolumn{2}{|c|}{$45-54$} & \multicolumn{2}{|c|}{55 and up } & \multirow{2}{*}{\begin{tabular}{|c|} 
Total \\
Frequency \\
\end{tabular}} & \multirow[b]{2}{*}{$\%$} \\
\hline & Frequency & $\%$ & Freq. & $\%$ & Freq. & $\%$ & Freq. & $\%$ & Freq. & $\%$ & & \\
\hline Yes & 120 & 76.92 & 66 & 72.53 & 62 & 65.96 & 16 & 53.33 & 7 & 41.18 & 271 & 69.85 \\
\hline No, but I'd like to learn about them & 13 & 8.33 & 14 & 15.38 & 18 & 19.15 & 10 & 33.33 & 5 & 29.41 & 60 & 15.46 \\
\hline No, and I'm not interested & 19 & 12.18 & 8 & 8.79 & 6 & 6.38 & 1 & 3.33 & 3 & 17.65 & 37 & 9.54 \\
\hline Don't know/Not sure & 4 & 2.56 & 3 & 3.30 & 8 & 8.51 & 3 & 10.00 & 2 & 11.76 & 20 & 5.15 \\
\hline Total & 156 & 100.00 & 91 & 100.00 & 94 & 100.00 & 30 & 100.00 & 17 & 100.00 & 388 & 100.00 \\
\hline
\end{tabular}


Table 6

QR Code Availability on Mobile Devices $(N=388)$

\begin{tabular}{|l|c|c|c|c|c|c|c|c|c|c|c|c|}
\cline { 2 - 14 } \multicolumn{1}{c|}{} & \multicolumn{10}{c|}{ Age } \\
\cline { 2 - 14 } \multicolumn{1}{c|}{} & \multicolumn{1}{c|}{$18-24$} & \multicolumn{2}{|c|}{$25-34$} & \multicolumn{2}{|c|}{$35-44$} & $45-54$ & 55 and up & Total & \\
\hline Answer & Frequency & $\%$ & Freq. & $\%$ & Freq. & $\%$ & Freq. & $\%$ & Freq. & $\%$ & Frequency & $\%$ \\
\hline Yes & 64 & 41.03 & 41 & 45.05 & 42 & 44.68 & 12 & 40 & 4 & 23.53 & 163 & 42.01 \\
\hline No & 57 & 36.54 & 37 & 40.66 & 38 & 40.43 & 11 & 36.67 & 10 & 58.82 & 153 & 39.43 \\
\hline Not sure & 35 & 22.44 & 13 & 14.29 & 14 & 14.89 & 7 & 23.33 & 3 & 17.65 & 72 & 18.56 \\
\hline Total & 156 & 100.00 & 91 & 100.00 & 94 & 100.00 & 30 & 100 & 17 & 100.00 & 388 & 100.00 \\
\hline
\end{tabular}

Shopping channels. Results clearly illustrated that the vast majority of the respondents prefer shopping at the bricks-and-mortar store over other channels (see Table 7). The possible explanation is that many respondents would like to touch and feel the fabric as well as to try on the garments prior to their purchase. As shown in Table 7, there are no significant differences between genders in terms of their preferences. Although mobile shopping was not fully embraced by respondents (only $7.7 \%$ ), it is reasonable to believe that the shopping paradigm is shifting or expanding (bricks-and-mortar $\rightarrow$ online $\rightarrow$ mobile). We have seen these shifts in the past from mail-order catalogue and ordering over the phone to online. For example, $72 \%$ of respondents $(n=272)$ indicated that they have experience with online purchases even though they were not using their mobile devices for those transactions. A recent IBM (2012) study reported that mobile traffic for retail increased 24\% in 2012, up from 14.3\% in 2011. Mobile sales reached 16\% in 2012, up from 9.8 in 2011 (IBM, 2012). In this sample, the respondents' preferred vendor for general online shopping was Amazon, followed by eBay merchants. For online apparel shopping, the top preferred stores according to respondents were Asos (asos.com), Nasty Gal (nastygal.com), SSense (ssense.com), Etsy (etsy.com), Forever 21, Urban Outfitters, and Victoria's Secret. 
Table 7

Significance of Shopping Channel

\begin{tabular}{|c|c|c|c|c|c|c|c|}
\hline \multicolumn{8}{|c|}{ Where do you shop for your clothes, footwear and accessories? $\mathrm{N}=380$} \\
\hline \multirow[b]{2}{*}{ Shopping Channel } & \multirow[b]{2}{*}{ Total (Percentage) } & \multicolumn{2}{|c|}{\begin{tabular}{c|c|} 
Female \\
\end{tabular}} & \multirow[b]{2}{*}{ Top 3} & \multicolumn{2}{|c|}{ Male } & \multirow[b]{2}{*}{ Top 3} \\
\hline & & Frequency & Percentage & & Frequency & Percentage & \\
\hline Regular retail store & 95.4 & 255 & 94.8 & 1 & 117 & 96.7 & 1 \\
\hline Outlet stores & 59.5 & 156 & 58.0 & 2 & 76 & 62.8 & 2 \\
\hline Retailer website & 45.1 & 128 & 47.6 & 3 & 48 & 39.7 & 3 \\
\hline Retailer mobile website & 7.7 & 21 & 7.8 & & 9 & 7.4 & \\
\hline Through a print catalogue & 4.6 & 14 & 5.2 & & 4 & 3.3 & \\
\hline Over the phone & 2.1 & 6 & 2.2 & & 2 & 1.7 & \\
\hline On TV & 0.8 & 3 & 1.1 & & 0 & 0.0 & \\
\hline Other & 2.6 & 8 & 3.0 & & 2 & 1.7 & \\
\hline
\end{tabular}

Apparel shopping-Significant selection criteria. As shown in Table 8, when making

clothes-shopping choices, style played the most significant role on overall apparel evaluation and selection, followed by price and size availability. The country of origin was ranked the least important evaluative cue, and this finding is consistent with several prior studies (Rahman, 2011; Rahman, Zhu, \& Liu, 2008). In other words, respondents were more concerned about the values of a product (style, price) rather than the country of production. Other than style and price, size availability also played an important role. Consumers may feel disappointed when they are unable to find their size available. The reason for not finding a size is not necessarily related exclusively to in-stock-item availability. The problem may also originate in a lack of availability from the source. For instance, some manufacturers only carry "regular' and not "plus" sizes.

When examining the past experience of online shopping for apparel, 53\% of female respondents purchased clothing and $44 \%$ accessories (see Figure 1), but only $37 \%$ chose online shopping as a mean to purchase footwear. Only $27 \%$ of male participants shopped online for footwear. It is reasonable to suggest that consumers are greatly concerned about the fit and comfort when it comes to footwear shopping. 
Table 8

Salient Apparel Selection Criteria*

\begin{tabular}{|l|c|c|c|}
\hline \multicolumn{4}{|c|}{ Apparel Selection Criteria N=390 } \\
\hline & Frequency & Mean & S.D. \\
\hline Style & 377 & 1.48 & 0.779 \\
\hline Price & 384 & 1.56 & 0.766 \\
\hline Sizes availability & 384 & 1.66 & 0.942 \\
\hline Textiles/materials & 386 & 1.85 & 0.936 \\
\hline Colour availability & 386 & 2.07 & 0.995 \\
\hline Ease of garment care & 382 & 2.85 & 1.238 \\
\hline Online review & 384 & 3.39 & 1.349 \\
\hline Technical performance & 387 & 3.41 & 1.319 \\
\hline Country of origin & 383 & 3.85 & 1.187 \\
\hline
\end{tabular}

* (1=least important to 5=most important $)$

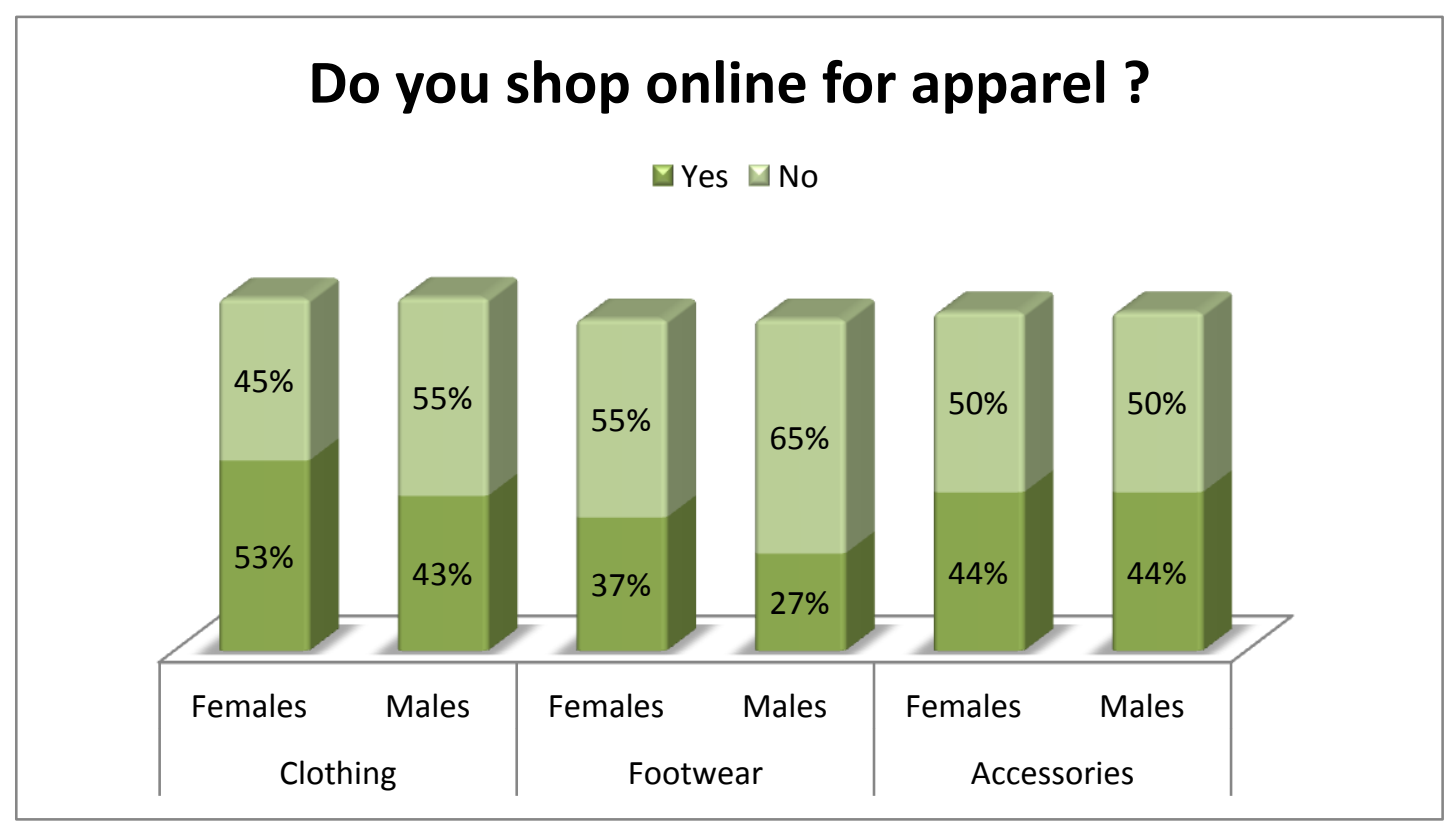

Figure 1. Apparel online shopping preferences by gender. 
It is interesting to note that when it comes to online apparel shopping, security issues such as intrusiveness or privacy concerns account for a very small amount (see Figure 2) of the reasons why respondents did not engage in online apparel purchases. It seems that respondents are now more confident in submitting personal information such as credit card details through online mediums. It would be reasonable to expect that since customers have gradually accepted to use their personal computers for online purchases they may also slowly shift to use their mobile devices for the same purpose.

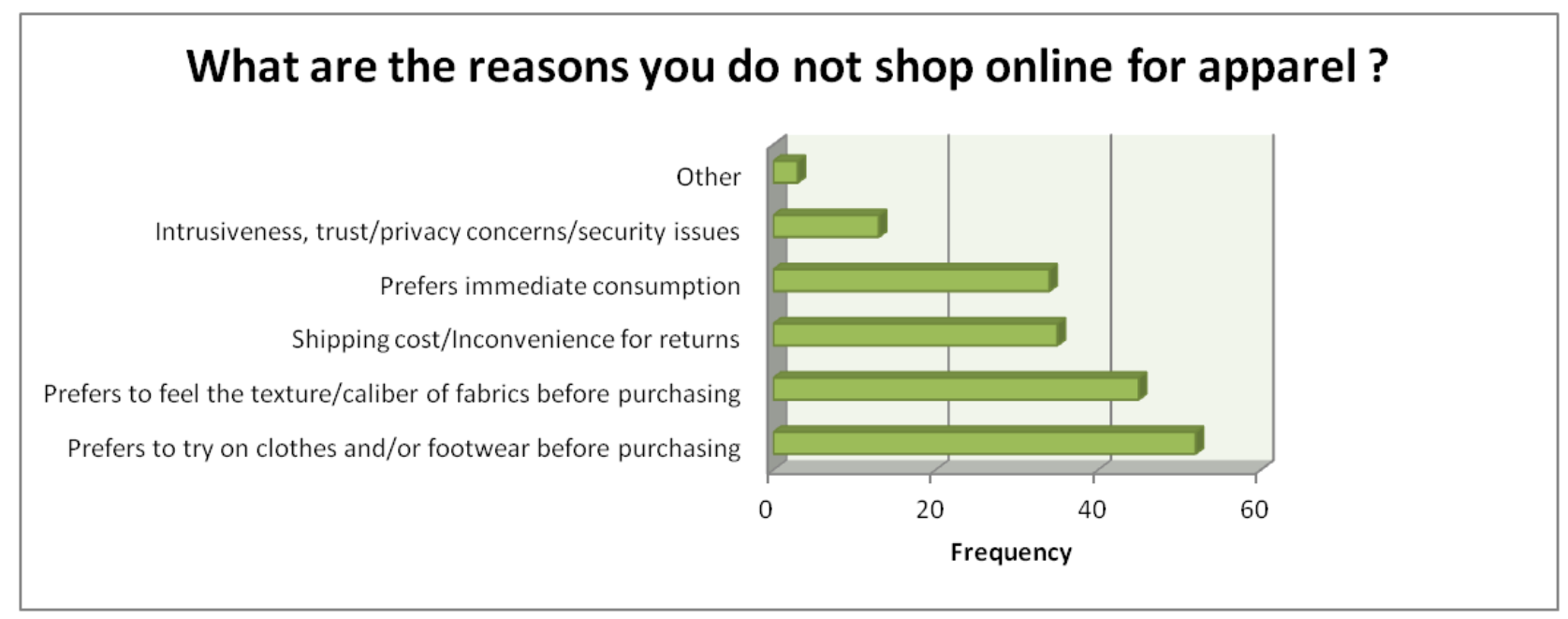

Figure 2. Respondents' rationale for avoiding online apparel shopping.

Apparel information sources. Respondents were asked about the information sources they consult for apparel purchase decision making. The measurement of the variables was done using a Likert scale where 1 was "Extremely important" and 5 "Not important at all."

The eight variables were subjected to principal components analysis (PCA) using SPSS version 20. Prior to performing PCA, the suitability of data for factor analysis was assessed. Inspection of the correlation matrix revealed the presence of many coefficients of .4 and above. The Kaiser-Meyer-Olkin value was .75, exceeding the recommended value of .6 (Kaiser, 1974) 
and Bartlett's Test of Sphericity (Bartlett, 1954) reached statistical significance ( $\mathrm{p}=.000)$, indicating significant relationships between variables; therefore, factor analysis was appropriate to use. Principal components analysis revealed the presence of two components with eigenvalues exceeding 1, explaining $37.2 \%$ and $15.9 \%$ of the variance, respectively. An inspection of the scree plot (Cattell, 1966) revealed a clear break between the first and the second components (see Figure 3), so it was decided to retain two components for further investigation. The two-factor solution explained a total of 53\% of the variance, with Component 1 contributing $37.2 \%$ and Component 2 contributing 15.9\%. To assist in the interpretation of these two components, Oblimin rotation with Kaiser's Normalization was performed. Rotation converged in 5 iterations. Reliability of the scale was tested with a reported Cronbach alpha coefficient of .76 which was acceptable because it was $>.7$.

Table 9

Significance of Apparel Information Source*

\begin{tabular}{|l|c|c|c|}
\hline \multicolumn{4}{|c|}{ Information sources for apparel decision making N=390 } \\
\hline & Frequency & Mean & S.D. \\
\hline Retail websites & 387 & 2.21 & 1.256 \\
\hline $\begin{array}{l}\text { Friends and family } \\
\text { recommendations }\end{array}$ & 388 & 2.31 & 1.124 \\
\hline Store display & 387 & 2.51 & 1.177 \\
\hline Customer's reviews & 384 & 2.89 & 1.327 \\
\hline Magazines & 389 & 2.94 & 1.221 \\
\hline Retail mobile websites & 385 & 3.27 & 1.379 \\
\hline Blogs & 383 & 3.48 & 1.242 \\
\hline TV ads & 384 & 3.7 & 1.17 \\
\hline
\end{tabular}

$*(1=$ extremely important to $5=$ not important at all $)$ 


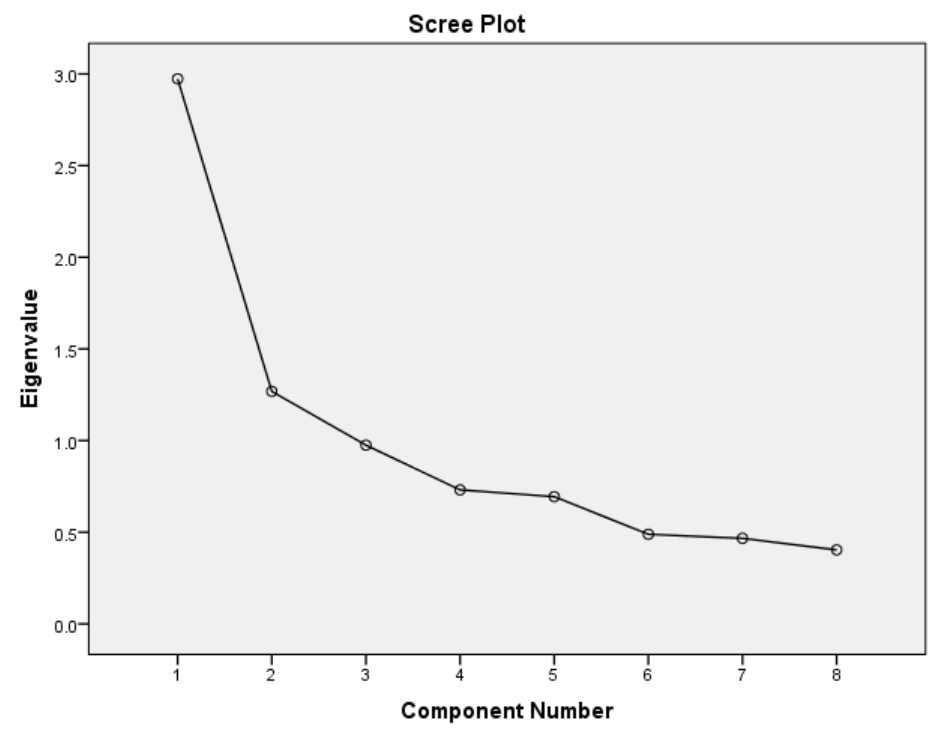

Figure 3. Scree plot with a clear inflection between the 1 st and 2 nd factors.

Table 10

Major Determinants of the Factors Derived by Exploratory Factor Analysis

\begin{tabular}{lccccc} 
& \multicolumn{2}{c}{ Pattern coefficients } & \multicolumn{2}{c}{ Structure coefficients } & Communalities \\
Item & Factor 1 & Factor 2 & Factor 1 & Factor 2 & \\
Customer reviews & $\mathbf{0 . 8 2 3}$ & -0.134 & $\mathbf{0 . 7 7 9}$ & 0.136 & 0.623 \\
Retail mobile websites & $\mathbf{0 . 6 8 5}$ & -0.014 & $\mathbf{0 . 6 8 1}$ & 0.211 & 0.464 \\
Blogs & $\mathbf{0 . 6 7 7}$ & 0.029 & $\mathbf{0 . 6 8 6}$ & 0.252 & 0.472 \\
Retail websites & $\mathbf{0 . 6 6 0}$ & 0.013 & $\mathbf{0 . 6 6 5}$ & 0.230 & 0.442 \\
Friends and family recommendations & 0.493 & 0.229 & $\mathbf{0 . 5 6 8}$ & 0.391 & 0.370 \\
Store display & -0.183 & $\mathbf{0 . 8 9 2}$ & 0.110 & $\mathbf{0 . 8 3 1}$ & 0.721 \\
Magazines & 0.104 & $\mathbf{0 . 7 5 7}$ & 0.352 & $\mathbf{0 . 7 9 1}$ & 0.635 \\
TV ads & 0.304 & $\mathbf{0 . 5 5 7}$ & 0.487 & $\mathbf{0 . 6 5 7}$ & 0.515
\end{tabular}

Factor 1 clustered four variables (see Table 10) with factor loadings $>.50$ indicating a strong relationship between the variables of apparel shopping information sources: customer reviews, retailers' websites (both regular and mobile), and blogs. At this point, Factor 1 could be labelled "Followers of online sources." The friends and family recommendation source loaded 
strongly in the structure matrix for Factor 1 as well. Perhaps this group could be viewed as one which takes advice from other people, such as bloggers, customer reviews, friends and family, and also takes information for decision making from retailers' websites. Factor 2 clustered three variables: store display, magazines, and TV ads; perhaps this group gets the information from more traditional sources, and at the same time they provide a non-customized or a more passive recommendation. Factor 2 could be labelled as "non-interactive."

Mobile communications. In terms of permission-based e-mail subscriptions, as shown in Table 11 , female respondents $(54 \%)$ were more willing to receive e-mail communications from their favourite apparel retailers than were males (only 33\%). Therefore retailers should focus their e-mail communications efforts primarily on women.

Table 11

E-mail Sign-up From Apparel Retailers

\begin{tabular}{|l|c|c|c|c|c|}
\hline \multicolumn{5}{|c|}{ Do you usually sign-up to receive e-mails from apparel retailers ? N=390 } \\
\hline & \multicolumn{2}{|c|}{ Female } & \multicolumn{2}{c|}{ Male } & \\
\hline Answer & Frequency & Percentage & Frequency & Percentage & Total \\
\hline Yes & 146 & 54.3 & 40 & 33.1 & 186 \\
\hline No & 123 & 45.7 & 81 & 66.9 & 204 \\
\hline Total & 269 & 100.0 & 121 & 100.0 & 390 \\
\hline
\end{tabular}

Respondents also gave their opinion about the desired frequency of such e-mail communications from apparel retailers: $32 \%$ of them thought once per month was adequate, $20 \%$ opted for two or three times per week, $19 \%$ once a week, $13 \%$ twice a month, and $13 \%$ daily. Opinions are fragmented, therefore careful consideration should be placed when sending e-mail communications. Retailers should find the right balance for their target customers; that is, whereby they maintain proper communication with clients and at the same time are not perceived 
as spam. Respondents who did not usually sign-up to receive e-mails from their favourite apparel retailers thought that receiving discounts and/or promotions would compel them to opt-in (62\%), followed by frequent shopper programs $(22 \%)$.

In regards to receiving SMS text messages (see table 12) from their favourite apparel retailers, an overwhelming amount of respondents (95\%) answered that they do not opt-in to receive such messages. This is an interesting finding, particularly because as we can see in Table $4,71 \%$ of respondents use SMS text messages on their smartphones. Text messaging actually occupied the second position in terms of mobile usage, right after 'making phone calls'. It seems users perceive SMS text messages to be of a more personal nature, therefore not sharing this communication channel with apparel retailers.

Table 12

SMS (Text) Messages Sign-up From Apparel Retailers

\begin{tabular}{|l|c|c|c|c|c|}
\hline \multicolumn{6}{|c|}{$\begin{array}{l}\text { Do you usually sign-up to receive SMS (text) messages from } \\
\text { your favourite apparel retailers ? N=389 }\end{array}$} \\
\hline & \multicolumn{2}{|c|}{ Female } & \multicolumn{2}{c|}{ Male } & \\
\hline Answer & Frequency & Percentage & Frequency & Percentage & Total \\
\hline Yes & 10 & 3.7 & 4 & 3.3 & 14 \\
\hline No & 257 & 95.5 & 115 & 95.0 & 372 \\
\hline Not familiar with SMS & 2 & 0.7 & 1 & 0.8 & 3 \\
\hline Total & 269 & 100.0 & 120 & 100.0 & 389 \\
\hline
\end{tabular}

Social networking and location-based services. In terms of social networks, Facebook maintained a hegemonic position (see Table 13). This social network is the second most visited website on the web, according to a Nielsen report cited by BBC News (2011). In this study, 92\% of female respondents were Facebook members, while $87 \%$ of their male counterparts had such membership. The second most sought after social network was Twitter, with almost equal 
amounts of gender participation. LinkedIn occupied the third place; however it is interesting to note that males $(46 \%)$ seem to be more interested in it than are females $(29 \%)$. Perhaps this could be explained because LinkedIn is mostly associated with professional relationships and for jobhunting, and stereotypes may play a role with males being the "breadwinners," thus using LinkedIn more than females. Respondents often belong to more than one social network.

Table 13

Most Popular Social Networking Websites

\begin{tabular}{|l|c|c|c|c|c|}
\hline \multicolumn{5}{|c|}{ Which social networking websites do you usually visit? N=390 } \\
\hline & \multicolumn{2}{|c|}{ Female } & \multicolumn{2}{c|}{ Male } & \\
\hline Social Network & Frequency & Percentage & Frequency & Percentage & Total \\
\hline Facebook & 248 & 92.2 & 105 & 86.8 & 353 \\
\hline Twitter & 132 & 49.1 & 60 & 49.6 & 192 \\
\hline LinkedIn & 78 & 29.0 & 55 & 45.5 & 133 \\
\hline Google + & 74 & 27.5 & 26 & 21.5 & 100 \\
\hline Stumble Upon & 25 & 9.3 & 4 & 3.3 & 29 \\
\hline Foursquare & 12 & 4.5 & 9 & 7.4 & 21 \\
\hline Does not visit social networks & 10 & 3.7 & 6 & 5.0 & 16 \\
\hline Pinterest & 10 & 3.7 & 5 & 4.1 & 15 \\
\hline Reddit & 9 & 3.3 & 6 & 5.0 & 15 \\
\hline Instagram & 9 & 3.3 & 1 & 0.8 & 10 \\
\hline Tumblr & 6 & 2.2 & 2 & 1.7 & 8 \\
\hline DIGG & 3 & 1.1 & 2 & 1.7 & 5 \\
\hline Delicious & 3 & 1.1 & 2 & 1.7 & 5 \\
\hline Other (We Heart It, Bright Kite) & 2 & 0.7 & 2 & 1.7 & 4 \\
\hline
\end{tabular}

Users of social networks have the option to "check-in" to a physical place and share their location with friends. Once "checked-in," users are sometimes able to earn discounts and rewards points. They also have the option of reading and/or leaving online comments about a place, which could be a retail store, a restaurant, or almost any place; users can also add places not currently listed. Foursquare, Google +, and Facebook's Places are examples of social 
networks who allow social "check-ins." Findings of this study revealed that there was a wide age gap in regards to social check-in. More mature participants were the least interested and had the least awareness about "check-ins" (see Table 14). The 18 to 24 age group was the most experienced. It is recommended that executive managers take into account these results to help them plan their social networks communications strategy and plan accordingly. Descriptions about retail stores can be uploaded, updated, and maintained as part of a social networking overall strategy. It would be beneficial to understand the age differences among target consumers, and perhaps even to educate potential clients who would be interested in engaging through this medium.

Table 14

“Check-in” Awareness for Social Networking

\begin{tabular}{|c|c|c|c|c|c|c|c|c|c|c|c|c|}
\hline \multirow[b]{4}{*}{ Answer } & \multicolumn{12}{|c|}{ Are you familiar with the concept of "check-in" for social networking sites and apps? $\mathrm{N}=390$} \\
\hline & \multicolumn{12}{|c|}{ Age } \\
\hline & \multicolumn{2}{|c|}{$18-24$} & \multicolumn{2}{|c|}{$25-34$} & \multicolumn{2}{|c|}{$35-44$} & \multicolumn{2}{|c|}{$45-54$} & \multicolumn{2}{|c|}{55 and up } & \multirow{2}{*}{$\begin{array}{l}\text { Total } \\
\text { Freq. }\end{array}$} & \multirow[b]{2}{*}{$\%$} \\
\hline & Frequency & $\%$ & Freq. & $\%$ & Freq. & $\%$ & Freq. & $\%$ & Freq. & $\%$ & & \\
\hline Yes I have heard of it & 73 & 46.79 & 37 & 40.66 & 32 & 34.04 & 8 & 26.67 & 3 & 17.65 & 153 & 39.43 \\
\hline Yes, I have checked in & 45 & 28.85 & 29 & 31.87 & 31 & 32.98 & 6 & 20.00 & 0 & 0.00 & 111 & 28.61 \\
\hline No, but I'd like to learn about them & 11 & 7.05 & 11 & 12.09 & 15 & 15.96 & 7 & 23.33 & 1 & 5.88 & 81 & 20.88 \\
\hline No, and I'm not interested & 28 & 17.95 & 14 & 15.38 & 17 & 18.09 & 9 & 30.00 & 13 & 76.47 & 45 & 11.60 \\
\hline Total & 157 & 100.00 & 91 & 100.00 & 95 & 100.00 & 30 & 100.00 & 17 & 100.00 & 390 & 100.00 \\
\hline
\end{tabular}

According to a recent IBM (2012) report, "social sales" or customers referred from social networks (Facebook, Twitter, LinkedIn, YouTube) generated $0.34 \%$ of all online sales during Black Friday 2012. As shown in Table 15, even though mobile users prefer to ask for live assistance from a store associate (71\%), it would be beneficial if apparel retailers maintain websites that are optimized for mobile device viewing. This would accommodate consumers who prefer to do research for decision making through their mobile devices as well. 
Table 15

In-Store Apparel Decision-Making Preferences When Customers Need Assistance

\begin{tabular}{|l|l|l|}
\hline \multicolumn{3}{|c|}{ While in-store apparel-decision-making } \\
Which from the following do you prefer if you need assistance? \\
$\mathrm{N}=390$
\end{tabular}

Taking photos with mobile devices for apparel decision making was not a common practice among respondents. Table 16 shows results when using an interval scale where 1=Always, 2=Usually, 3=Sometimes, 4=Seldom/Few times, 5=Never, and 6=Prefers not to answer.

Table 16

Usage of Mobile Device Camera for Apparel Decision Making

\begin{tabular}{|l|c|c|c|}
\hline \multicolumn{3}{|c|}{ Usage of mobile device camera for apparel decision making } \\
\hline Photo usage of apparel items & Frequency & Mean & S.D. \\
\hline $\begin{array}{l}\text { Takes photos of self inside the } \\
\text { fitting room, to see if item "looks } \\
\text { good" }\end{array}$ & 389 & 4.17 & 1.112 \\
\hline $\begin{array}{l}\text { Takes photos of self inside the } \\
\text { fitting room and sends them to } \\
\text { friends asking for opinion }\end{array}$ & 385 & 4.17 & 1.107 \\
\hline $\begin{array}{l}\text { Takes photos of preferred } \\
\text { apparel items and shares them } \\
\text { on social media }\end{array}$ & 387 & 4.58 & 0.859 \\
\hline $\begin{array}{l}\text { Takes photos of apparel items } \\
\text { and suggests them to friends }\end{array}$ & 385 & 4.11 & 1.114 \\
\hline $\begin{array}{l}\text { Takes photos of preferred } \\
\text { apparel items and saves them } \\
\text { for later to show friends }\end{array}$ & 388 & 4.02 & 1.083 \\
\hline
\end{tabular}


Mobile play. Survey data from the United States Bureau of Labor Statistics (2011) reveals that individuals aged 15 to 19 years old spend an average of 1.2 hours (72 minutes) per day playing games on any given platform. According to Flurry Analytics (as cited in Farago, 2012), games are the most profitable app category. Flurry Analytics estimate games take about $80 \%$ of the total apps market, and that users spend $43 \%$ of within-mobile-apps-time playing games. "Freemium" business models, where users download basic versions of games free of charge, profit by selling access to more advanced levels or enhanced versions of the gaming app. They also prosper when gamers purchase virtual currency or goods to use while playing. To reach the rest of the users who do not spend "real" money, such businesses still thrive by displaying advertisements while they play (Laughlin, 2012). In this research, 52\% of respondents were players. Gaming was most frequent among the youngest group of 18-24 year olds (54\%) followed by the 35-44 age group (53\%). (See Table 17.) The most cited game played was "Angry Birds"; however, "fashion" in games changes rather frequently. As of this writing, "Candy Crush" seems to be the new fashionable game according to informal and anecdotal information gathered by this researcher.

\section{Table 17}

\section{Videogames/Online Games Participation}

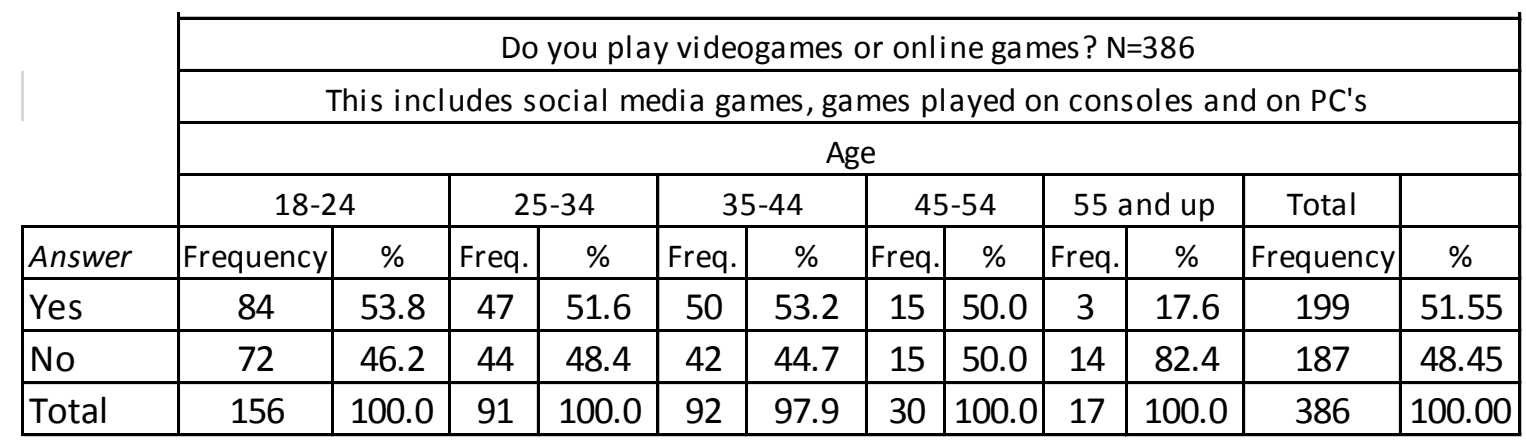


Most respondents had not downloaded games from retailers $(\mathrm{n}=326)$. Downloading such games was more popular among males than females (27\% vs. only $10 \%)$. If retailers are considering the addition of a gaming component to an app or as part of a contest, then this information may help them plan their strategy accordingly. Retailers may also consider advertising within pervasive gaming apps.

Table 18

Games from Retailers Engagement

\begin{tabular}{|l|c|c|c|c|c|}
\hline \multicolumn{5}{|c|}{ Have you ever downl oaded games from retailers? N=385 } \\
\hline & \multicolumn{2}{|c|}{ Female } & \multicolumn{2}{c|}{ Male } & \\
\hline Answer & Frequency & Percentage & Frequency & Percentage & Total \\
\hline Yes & 26 & 9.8 & 33 & 27.3 & 59 \\
\hline No & 238 & 90.2 & 88 & 72.7 & 326 \\
\hline Total & 264 & 100.0 & 121 & 100.0 & 385 \\
\hline
\end{tabular}

Apps. Mobile apps now seem to directly compete with other more traditional advertising media such as regular web browsing from a PC and television. Flurry Analytics reports that the average time spent within mobile apps increased 35\% from 94 minutes in 2011 to 127 minutes in 2012 (as cited in Farago, 2012). This comes in second place right after television with an average of 168 minutes per day and before web browsing with an average 70 minutes per day. Flurry Analytics also forecast that with the introduction of smart televisions and the synchronization of TV shows on tablets, TV shows will gradually start behaving more like apps (Khalaf, 2012).

Findings show that $76 \%$ of respondents had not downloaded apparel retailer's apps to their mobile devices (see Table 19). However, $22 \%$ of respondents had downloaded apparel retailers' apps. Perhaps this percentage belongs to a group of "innovators" or "early adopters" (Rogers, 1995). Future research could explore the reason for adoption; other possible scenarios are a lack 
of awareness or interest. Some of the apps that respondents had downloaded were from

Nordstrom, Target, Zara, and H\&M.

Table 19

Level of Apparel Retailers' Apps Engagement

\begin{tabular}{|c|c|c|c|c|c|}
\hline \multicolumn{6}{|c|}{ Have you downloaded any apparel retailer's apps to your mobile device? $\mathrm{N}=388$} \\
\hline & \multicolumn{2}{|c|}{ Female } & \multicolumn{2}{|c|}{ Male } & \multirow[b]{2}{*}{ Total } \\
\hline Answer & Frequency & Percentage & Frequency & Percentage & \\
\hline Yes & 59 & 22.3 & 28 & 23.1 & 87 \\
\hline No & 203 & 76.9 & 92 & 76.0 & 295 \\
\hline Not familiar with apps & 5 & 1.9 & 1 & 0.8 & 6 \\
\hline Total & 267 & 100.0 & 121 & 100.0 & 388 \\
\hline
\end{tabular}

In terms of features that an apparel retailer's app could have an interval scale was used where $1=$ not important at all, and 5=very important (see Table 20). A store locator feature was the most popular answer, with a mean of 4.06 , followed by a comparison feature and the ability to link the display of products in use whether as a video (for instance in a runway) or in an image. The least important feature was the ease of sharing photos of products with friends.

Table 20

Potential App Features*

\begin{tabular}{|l|c|c|c|}
\hline \multicolumn{3}{|c|}{ Level of desirability of features for an apparel retailer's app N=390 } \\
\hline Features to include & Frequency & Mean & S.D. \\
\hline A store locator feature & 379 & 4.06 & 1.081 \\
\hline A comparison feature & 375 & 3.56 & 1.191 \\
\hline $\begin{array}{l}\text { The ability to link to a video or } \\
\text { image to see the product in use } \\
\text { or in a runway }\end{array}$ & 382 & 3.28 & 1.284 \\
\hline $\begin{array}{l}\text { Ease of sharing products' photos } \\
\text { with friends }\end{array}$ & 369 & 2.48 & 1.416 \\
\hline
\end{tabular}

$*(1=$ not important at all to $5=$ very important $)$ 
M-Commerce. Male respondents were the most experienced when it came to $\mathrm{m}$ commerce. The most frequent form of mobile payments for males was app purchasing, followed by music and movie tickets (see Table 21). Fifty-one percent of females had no m-commerce experience in comparison with $40 \%$ of males. Female respondents also cited music as the most frequent form of engaging in mobile payments (34\%) followed by music (28\%) and movie tickets (20\%). Respondents had spent an average of $\$ 2.32$ per downloaded app.

There are several ways in which consumers can pay using their mobile device (e.g., typing their credit card details on a webpage; using Paypal; or "in-app billing"); companies such as Bango allow app developers to bill for items within the app across different platforms. According to TechCrunch, Bango has become the preferred mobile payments platform for the world's leading app stores, such as BlackBerry App World and Google Play (as cited in Lunden, 2012). Bango also provides payment services to Amazon and Facebook, and is a technology partner with MasterCard's Paypass mobile wallet (Lunden, 2012). With Amazon's 1-click, customers pre-register their credit card details, delivery address, and billing information, enabling clients to to make quick purchases using the 1-click payment system, which also works for mobile devices (Skeldon, 2011). Another form of mobile payment is by purchasing a prepaid card (for instance an iTunes card, or a Starbucks card) and withdraw payments from there. Another more modern form is to use the Paypass Mastercard system which uses Near Field Communication (NFC) to process the transaction. As of this writing, the most recent innovation in mobile payments was launched by American Express, which teamed up with Twitter to develop the "Twitter sync" feature that enables customers (who have synced their Amex account details with Twitter) to make mobile payments of selected products (such as Amazon's Kindle 
Fire and products from Sony, Urban Zen, and Xbox) by tweeting purchase hashtags (Lomas, 2013).

Table 21

Mobile Payments Profile

\begin{tabular}{|c|c|c|c|c|c|}
\hline \multicolumn{6}{|c|}{ Have you ever purchased something with your smartphone or tablet? N=390 } \\
\hline & \multicolumn{2}{|c|}{ Female } & \multicolumn{2}{|c|}{ Male } & \multirow[b]{2}{*}{ Total } \\
\hline Answer & Frequency & Percentage & Frequency & Percentage & \\
\hline Has no experience with mobile purchases & 137 & 50.9 & 48 & 39.7 & 185 \\
\hline An app & 90 & 33.5 & 61 & 50.4 & 151 \\
\hline Music & 76 & 28.3 & 37 & 30.6 & 113 \\
\hline Movie tickets & 54 & 20.1 & 34 & 28.1 & 88 \\
\hline Pizza & 23 & 8.6 & 9 & 7.4 & 32 \\
\hline Other & 15 & 5.6 & 10 & 8.3 & 25 \\
\hline Coffee & 17 & 6.3 & 3 & 2.5 & 20 \\
\hline Other Fast food & 11 & 4.1 & 4 & 3.3 & 15 \\
\hline
\end{tabular}

Mobile payments are still at an infancy stage; however, if embraced, retailers could facilitate the check-out process for customers by engaging in m-commerce. It seems that it is still too early to tell the direction these mobile payments will take. Respondents who lacked mcommerce experience mentioned no perceived value ("not finding it necessary") to engage in these transactions at this point; other reasons included intrusiveness and security issues, some find it "too uncomfortable," and others fear their phones may get lost or stolen, which poses important safety concerns regarding mobile payments. One respondent mentioned: "service provider costs, [I] already pay for Internet usage for my computer." In this example the respondent perhaps does not feel the need to pay for a wireless service provider, therefore remaining with a fixed-location Internet.

Credit cards with a Paypass feature involve the use of Near Field Communication (NFC) technology to pay by simply "waving" or "tapping" the credit card without the need to introduce 
a pin number into a merchant's keypad or a signature. Forty-five percent of respondents believe their credit card does not have a Paypass feature; $28 \%$ have "tapped" their credit card to make a payment. In this sample, the 55 years and older age group had the most experience with these payments (see Table 22). If consumers show confidence and have positive experiences using their NFC-enabled credit card, this in turn could lead to the gradual adoption of NFC mobile payments for future transactions.

Table 22

Use of Paypass Feature for Mobile Payments

\begin{tabular}{|c|c|c|c|c|c|c|c|c|c|c|c|c|}
\hline \multirow[b]{4}{*}{ Answer } & \multicolumn{12}{|c|}{ Have you ever "tapped" using the Paypass feature to pay for something? N=389 } \\
\hline & \multicolumn{12}{|c|}{ Age } \\
\hline & \multicolumn{2}{|c|}{$18-24$} & \multicolumn{2}{|c|}{$25-34$} & \multicolumn{2}{|c|}{$35-44$} & \multicolumn{2}{|c|}{$45-54$} & \multicolumn{2}{|c|}{55 and up } & \multirow{2}{*}{\begin{tabular}{|c|} 
Total \\
Frequency \\
\end{tabular}} & \multirow[b]{2}{*}{$\%$} \\
\hline & Frequency & $\%$ & Freq. & $\%$ & Freq. & $\%$ & Freq. & $\%$ & Freq. & $\%$ & & \\
\hline Has "tapped" to pay & 49 & 31.2 & 27 & 29.7 & 20 & 21.3 & 7 & 23.3 & 7 & 41.2 & 110 & 28.28 \\
\hline Has not used the Paypass feature & 24 & 15.3 & 9 & 9.9 & 2 & 2.1 & 1 & 3.3 & 2 & 11.8 & 38 & 9.77 \\
\hline Credit card does not have the Paypass feature & 58 & 36.9 & 34 & 37.4 & 61 & 64.9 & 16 & 53.3 & 6 & 35.3 & 175 & 44.99 \\
\hline Not sure if credit card has Paypass feature & 8 & 5.1 & 10 & 11.0 & 10 & 10.6 & 4 & 13.3 & 1 & 5.9 & 33 & 8.48 \\
\hline Does not have a credit card & 18 & 11.5 & 11 & 12.1 & 1 & 1.1 & 2 & 6.7 & 1 & 5.9 & 33 & 8.48 \\
\hline Total & 157 & 100.0 & 91 & 100.0 & 94 & 100.0 & 30 & 100.0 & 17 & 100.0 & 389 & 100.00 \\
\hline
\end{tabular}




\section{Chapter Five: Conclusions}

\section{Outlook of M-Commerce}

It is reasonable to expect that consumers will increasingly adopt mobile technologies to engage with their favourite fashion retailers in the future. We have previously experienced these "shifts" from mail-ordering to online shopping, therefore it is plausible to expect the gradual adoption of mobile shopping. If consumers show confidence and have positive experiences (for instance, using their NFC-enabled credit card), this in turn could lead to the steady adoption of NFC mobile payments for future transactions. Mobile payments are still at an infancy stage, however if embraced, retailers could facilitate the check-out process for customers by engaging in m-commerce.

Retailers should find ways to overcome consumers' concerns for privacy/security, to make their apps and mobile websites convenient and easy to use, and even to educate shoppers in the use of apps, Wi-Fi enablement, QR code scanning, and/or to pinpoint the location of digital look-books. It is advisable to create a consistent experience across channels, whereby clients can go from website to mobile website to a bricks-and-mortar store, and have a seamless and consistent experience.

\section{Mobile Communications}

There were distinct gender differences among respondents in regards to mobile device usage. For instance, female participants used SMS text messaging services more frequently and had a reported higher usage of the cameras on their mobile devices than their male counterparts who preferred activities like web browsing and to go through their email accounts. Also, female respondents were more willing to receive e-mail communications from their favourite apparel retailers (54\%) than males (only 33\%). Therefore retailers may focus their e-mail 
communications efforts primarily on women. Opinions about the desired frequency of such email communications are fragmented, therefore careful consideration should be placed when sending e-mails. Retailers should find the right balance for their target customers, that is, where they maintain proper communication with clients and at the same time, are not perceived as spam. Findings showed that consumers may feel compelled to opt-in to receive emails when they are offered discounts. In terms of SMS text message subscriptions from apparel retailers, it is not recommended that retailers engage clients through this communication channel. Users clearly responded that they usually do not opt-in for receiving such messages from retailers. It is possible that SMS text messaging is perceived to be of a more personal nature.

It would be beneficial if apparel retailers maintain websites that are optimize $\mathrm{d}$ for mobile device viewing. This helps shoppers access information wherever they are as long as they have an Internet connection available.

Wi-fi provides an interesting alternative to regular telecom carriers. Within bricks-andmortar retail stores, or at shopping malls, Wi-Fi enablement may give a competitive advantage for communicating and interacting with customers. Shoppers may experience a more friendly and interactive shopping environment, and at the same time, retailers can effectively overcome inherent communication problems. Wi-Fi is a tool that can help (a) overcome communication issues with clients who are from out of town and do not have a local data plan; (b) retail locations that are underground or otherwise have signal problems (due to location, a crowded environment, thick concrete walls, metal furniture, etc.); and (c) users of iPod Touch or similar devices, who only rely on Wi-Fi for Internet access. Wi-Fi can also act as an empowerment 
tool for employees; for example, tablets can be distributed among employees to help illustrate points, product uses, or otherwise showcase information to clients.

Apparel retailers may use QR codes within their stores to enhance the customer shopping experience. A QR code can be placed as a merchandise hangtag and customers can get further product information when they scan it. QR codes may also be placed in close proximity to merchandise, and when scanned, they can link to an online video (which could be setup in Youtube). This video may have promotional content, suggested product combinations (such as "this blouse goes well with this skirt") or instructions about product use (such "how to tie a scarf” and, “different ways a scarf can be worn”). QR codes may also link users to an audio file, such files may contain directions or guidance for shoppers. Apparel retailers may create a wide range of exciting experiences for customers through creative QR code use. A sign placed in a storefront window inviting passerby shoppers to "scan this for a free item" or to get a discount, may prove to be an efficient way to engage them.

\section{Social Networking}

To enhance web development efforts, retailers also need to constantly monitor platform preferences among users (e.g. Apple's iPhone now has a hegemonic presence, but this could

change; after all, BlackBerry once had a prime position, and then lost it). It would be beneficial for retailers to engage their customers through social media efforts (e.g., Facebook pages, corporate Twitter accounts, monitoring customers' reviews, etc.) and to be aware of users' preferences, because new players enter social networks, and sometimes they can have a great influence in a very short period of time (two recent examples being Instagram and Pinterest). In terms of social networks, Facebook still maintains a hegemonic position, at least for now. This is a fast-paced environment. Mobile users enjoy being in contact with friends, engaging 
with their favourite retail businesses through social networks, and being informed about discounts or special promotions and events. With this perspective, it is advisable for fashion marketers and retailers to connect and communicate with their consumers through social networking and mobile devices.

\section{Apps and Mobile Gaming}

Mobile gaming is one of the most popular activities among mobile device users. Depending on the product and target market, retailers may choose to advertise within pervasive gaming apps (advergaming), or engage consumers/game players in creative ways, perhaps integrated into the gaming experience; however, this needs careful planning and testing.

Apparel retailers may benefit by developing their own branded app. It should be perceived as an added convenience for the shopper, and features may include barcode scanning, inventory status, look-books, store locator (and hours) information, product information and reviews, and social media features. The app may also have a GPS component for tracking customers; if they opt-in or their device is enabled, this could alert them of promotions or special events when they are nearby. At the same time, this information may also help to develop more meaningful CRM databases.

\section{Contribution}

The purpose of this study was to gain a deeper understanding about consumer behaviour and preferences regarding mobile devices that would help strengthen the mobile marketing mix for apparel retailers. The effective use of mobile marketing efforts may enhance sales and customer loyalty. Since this topic is still in its infancy stage, this study is expanding current knowledge about mobile marketing in apparel retail and hopefully can contribute to help executives in their managerial decision making. 


\section{Limitations}

This research used judgmental and convenience sampling which have inherent statistical limitations due to their non-probabilistic nature. Therefore a future study that utilizes a probabilistic approach could strengthen results. Also, qualitative research methods can be employed to gain a deeper understanding of consumers' perceptions and preferences about mobile marketing efforts from apparel retailers. A single study should not form the basis for generalizations. Therefore, more replication is needed to strengthen the data validity and reliability. In addition to this point, cross-cultural/longitudinal replication of this type of study could be beneficial.

\section{Future Research}

We are beginning to learn more about consumer behaviour and perceptions towards mobile devices and how they can be useful tools for apparel retailers. However this is a broad topic, so future research could focus on further exploring areas such as the role of different social media platforms in mobile marketing; a deeper exploration into augmented-reality and its uses; the effectiveness level of mobile advertising; further study about mobile payments in apparel; and the enhancement of location-based services in order to improve retail customers' in-store experience.

\section{Conclusion}

Mobile devices and online platforms change very rapidly, therefore it is a challenge for researchers to keep up with new technology advancements. Companies like Instagram and Pinterest have gained popularity among consumers in a relatively short period of time. The mobile horizon can change in a matter of months, certain markets may reach points of saturation, and new business propositions emerge seemingly every day. Therefore apparel 
businesses should carefully and constantly monitor new trends in social media and consumers' adoption of new mobile devices, and find the right balance in their mobile marketing mix that will keep their customers coming back. We are witnessing the start of deeper and more meaningful consumer relationships, and mobile devices and their respective apps are making this increasingly possible. 


\section{Appendix A: Online Survey Consent Form}

Thank you for participating on this research study about Mobile Marketing for Apparel Retailers conducted by Ivonne Serna under the supervision of Prof. Osmud Rahman of Ryerson University, Canada. The study is for a Master's thesis.

By volunteering, you will be asked to complete a 20-30 minute online survey that is completed anonymously. Survey questions focus on usual use of your smartphone and about your apparel shopping preferences. Participation in this study is voluntary. You may decline to answer any questions that you do not wish to answer and you can withdraw your participation at any time, you may simply close your web browser and no data will be submitted. There are no known or anticipated risks from participating in this study.

It is important for you to know that any information that you provide will be anonymous. All of the data will be summarized and no individual could be identified from these summarized results. Furthermore, the web site is programmed to collect responses alone and will not collect any information that could potentially identify you (such as machine identifiers).

The data, with no personal identifiers, collected from this study will be maintained on a password-protected computer database in a restricted access area of the university. As well, the data will be electronically archived after completion of the study and maintained for three years and then erased.

Should you have any questions about the study, please contact either Ivonne Serna (Isernaze@ryerson.ca) or Osmud Rahman (orahman@ryerson.ca) Ph: 416-979-5000 x. 6911 or Ryerson University's Research Ethics Board at extensions 6300 or 7112.

We would like to assure you that this study has been reviewed and received ethics clearance through the Research Ethics Board at Ryerson University. However, the final decision about participation is yours. Thank you for participating in this study.

Consent of Participant

By clicking on this consent form $\square \checkmark$, you are not waiving your legal rights or releasing the investigator or Ryerson University from their legal and professional responsibilities.

I have read and understood the above information. I am aware that I may withdraw from the study at any time by just closing the web browser.

With full knowledge of all foregoing, I agree, of my own free will, to participate in this study. Please click here to agree $\square$ and to begin the questionnaire . 


\section{Appendix B: Online Survey Questions}

1. Do you own a Smartphone, Tablet or e-Reader? Which one? Please check all that apply:

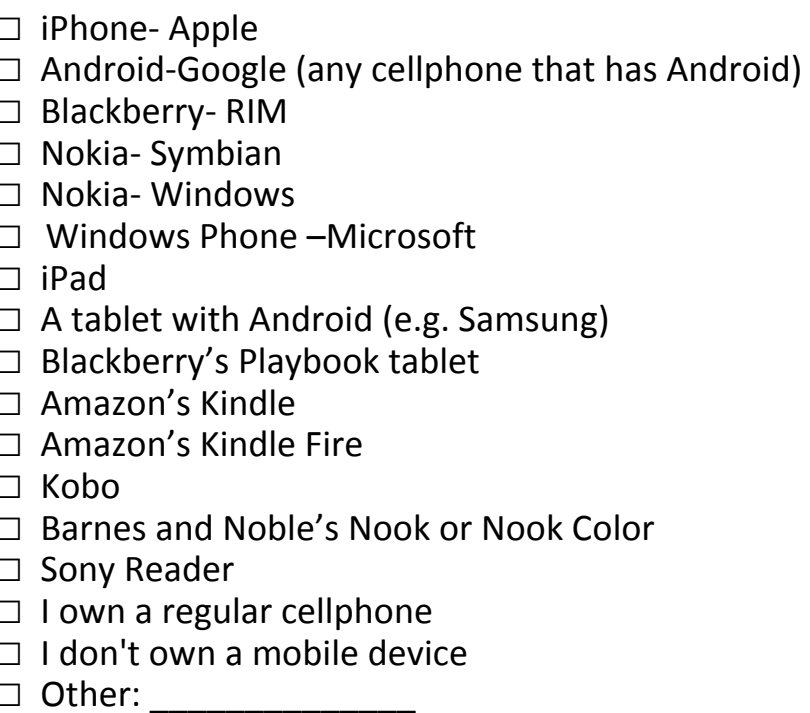

2. How many Smartphones do you have? Please indicate a number.

Smartphones

3. How many Tablets do you have? (including e-readers). Please indicate a number. Tablets

4. What do you use your device for? Please check all that apply:
$\square$ Play games
$\square$ Browse the Internet
$\square$ Use apps
Compare items/prices
Listen to music
Watch videos
$\square$ Take photos/sharing them
Phone calls
Text messaging (SMS)
$\square$ Scan QR/Bar Codes
E-mail
News/weather/traffic/sports
$\square$ Maps/directions (GPS)
Translator
Read blogs
Read a book

Social Media (Twitter, Facebook, Foursquare, etc.)

5. How long have you been using your mobile device? Example " 1 year with my iPad, 6 months with my iPhone".

6. Do you have a data plan with your mobile service provider? (A data plan gives the user access to the Internet wherever their mobile provider has coverage).

$\square$ Yes $\quad \square$ No $\quad \square$ I only access the internet through Wi-Fi

7. Do you receive e-mails on your mobile device? For example forwarding services from Hotmail, Yahoo Mail, Gmail, Microsoft Outlook, etc?

$\square$ Yes $\square$ No 
8. Are you familiar with the use of QR codes? Here below is an illustration of one.

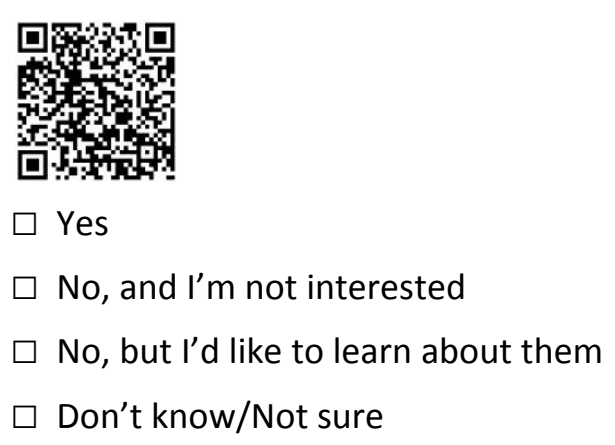

9. Do you have a QR Code reader or scanner application in your mobile device?

$\square$ Yes

$\square$ No

$\square$ Not Sure

10. Do you shop online? For example: Amazon, Best Buy, Zappos, Macy's, etc.?

$\square$ Yes

$\square$ No

11. What are your preferred stores for online shopping?

12. From which device do you shop online most often? Please check only one.

$\square$ PC (Windows)

$\square$ Mac (Apple)

$\square$ Smartphone

13. Where do you shop for your clothes, footwear and accessories? Please check all that apply.

At a store (that you visit in person)

Outlet stores

Retailer website (e.g. Macy's, Nine West, The Bay, Amazon, etc.)

Retailer's mobile website (shopping from your mobile device)

Through a print catalogue

Over the phone

On TV (e.g. Home Shopping Network, QVC, etc.)

Other 
14. Thinking about the aspects that you take into account when purchasing apparel. Please rate the following attributes using a scale of $5=$ Extremely important to $1=$ Not important at all.

\section{Extremely}

important

5

*Availability of colors

*Textiles, blends and materials

*Price

*Availability of sizes

*Style

*Country of origin/where garment

was made

* Ease of garment care (e.g.machine washable vs. dry clean)

*Technical information (for example, "withstands $-30^{\circ} \mathrm{C}$ temperatures")

*Customers' online reviews

$\square$
Not important

at all

1

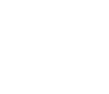

$\begin{array}{lll}4 & 3 & 2\end{array}$

$\square \quad \square \quad \square$

$\square$

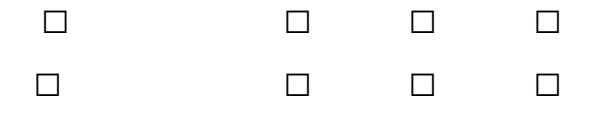

$\square$ 
16. Do you shop online for apparel (Clothing / Footwear / Accessories)? For example: Victoria's Secret, Macy's, Christian Louboutin, Michael Kors, The Bay, Sears, Columbia, etc. Please check all that apply:
$\square$ Yes (Clothing)
Yes (Footwear)
Yes (Accessories)
No (Clothing)
No (Footwear)
No (Accessories)

17. What are your preferred stores for online apparel shopping?

18. What are the reasons you do not shop for apparel online? (Please check all that apply)
$\square$ I do not have a credit/debit card
$\square$ I prefer to try on clothes and/or footwear before purchasing
$\square$ I prefer to have my products right away
$\square$ I prefer to buy through a catalog or over the phone
$\square$ Shipping cost / Inconvenience for returns
$\square$ I'm not sure how to shop online/Have not tried it

$\square$ Intrusiveness, trust / privacy concerns /disclosure of personal information/security issues

$\square$ I prefer to feel the texture/caliber of the fabric of garments before purchasing

19. If you are at a store (that you visit in person), while in the process of purchasing apparel, and need assistance or have a question, which would you prefer from the following? Please check all that apply.

$\square$ Ask a store associate for assistance.

$\square$ I prefer to do my own research with my mobile device

$\square$ Both

20. If you prefer to do your own research with your mobile device. Which of the following options do you prefer? Please select the most important. Please make only one selection.

$\square$ I call a friend or relative for their opinion

$\square$ I visit the retailer's own website for client's reviews

$\square$ I visit different websites for client's reviews or comparisons

$\square$ I visit different websites for product information

$\square$ I visit specialized blogs

21. Thinking about taking photographs with your mobile device while deciding to purchase apparel. Please indicate the frequency of the following possible scenarios when taking pictures.

Always Usually Sometimes Seldom/Few times Never Prefer Not to Answer

*I take photographs

in the fitting room

or when trying on an

apparel item to see

how it looks on me

*I take photographs

in the fitting room or

when trying on an 


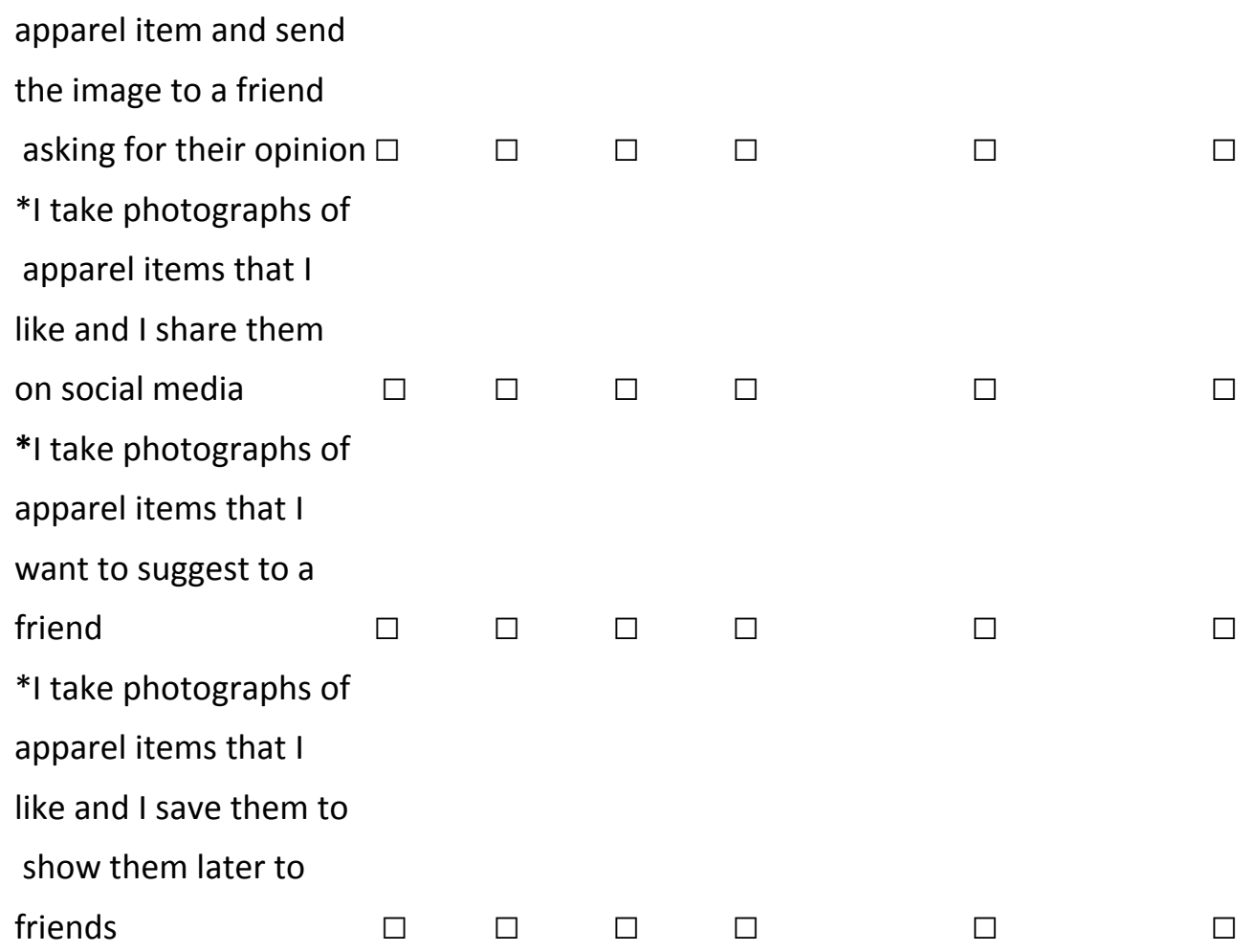

22. Do you play videogames or online games? This includes social media games such as Farmville, SongPop, Angry Birds, etc.; games played on consoles (Xbox, Kinect, Wii, Playstation) and on PC's.

Yes

$\square$ No

23. Which video game/online game do you play the most?

24. Where do you usually play videogames? Please indicate the frequency on each device.

Always Usually Sometimes Seldom/Few times Never/Not applicable

*Smartphone

*Tablet (iPad, Samsung, Playbook, etc.)

*PSP, PS Vita or other portable gaming system

*Console (Xbox, Play Station, Wii, etc.)

*PC or Mac

25. Have you ever downloaded games from retailers? For example, scavenger hunts or other games in order to earn points, prizes or participate in special promotions?

$\square$ Yes.

$\square$ No 
26. Please specify from which retailer(s) you have downloaded games.

27. Have you ever paid for downloading an app to your mobile device?

$\square$ Yes

$\square$ No

$\square$ I'm not familiar with apps

28. If you have paid for downloading an app. How much in average did it cost? Please specify an approximate amount in dollars.

29. Have you downloaded any apparel retailer's apps to your mobile device? For example, Target, Canadian Tire, Macy's, Etsy, etc.

$\square$ Yes

$\square$ No

$\square$ I'm not familiar with apps

30. Please mention which retailer's apps you have downloaded.

31. If you have a tablet, do you read magazines on this device?

$\square$ Yes

$\square$ No

$\square$ I'm not familiar with reading magazines on this device

32. Which magazines do you read on your tablet?

33. Thinking about the desired features that an apparel retailer's app could have, please indicate the importance of the following capabilities:

$\begin{array}{llllll}\begin{array}{l}\text { Very } \\ \text { important }\end{array} & & & & \begin{array}{l}\text { Not important } \\ \text { unimportant }\end{array} & \begin{array}{l}\text { N/A } \\ \text { at all }\end{array} \\ 5 & 4 & 3 & 2 & 1 & \end{array}$

Ease of sharing favorite products'

photos with friends ("Like" Facebook button

Pin it on Pinterest, etc. ।
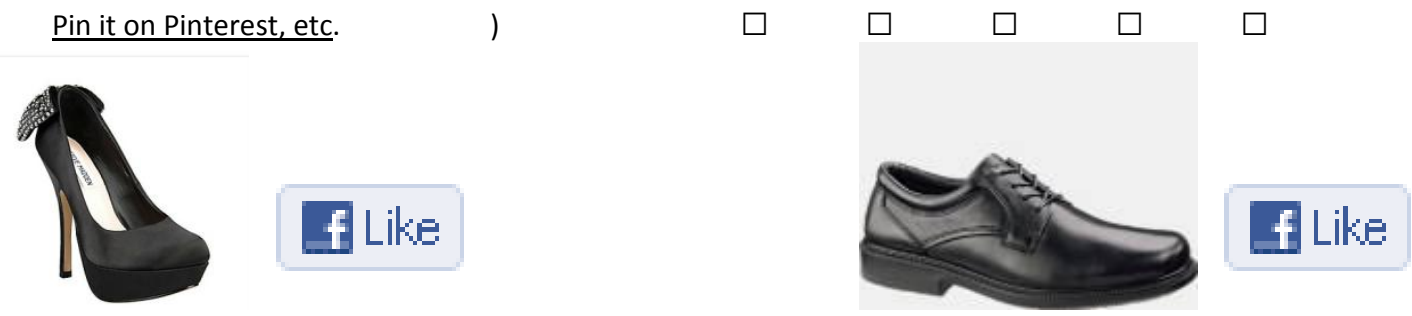
34. Thinking about the desired features that an apparel retailer's app could have, please indicate the importance of the following capabilities:

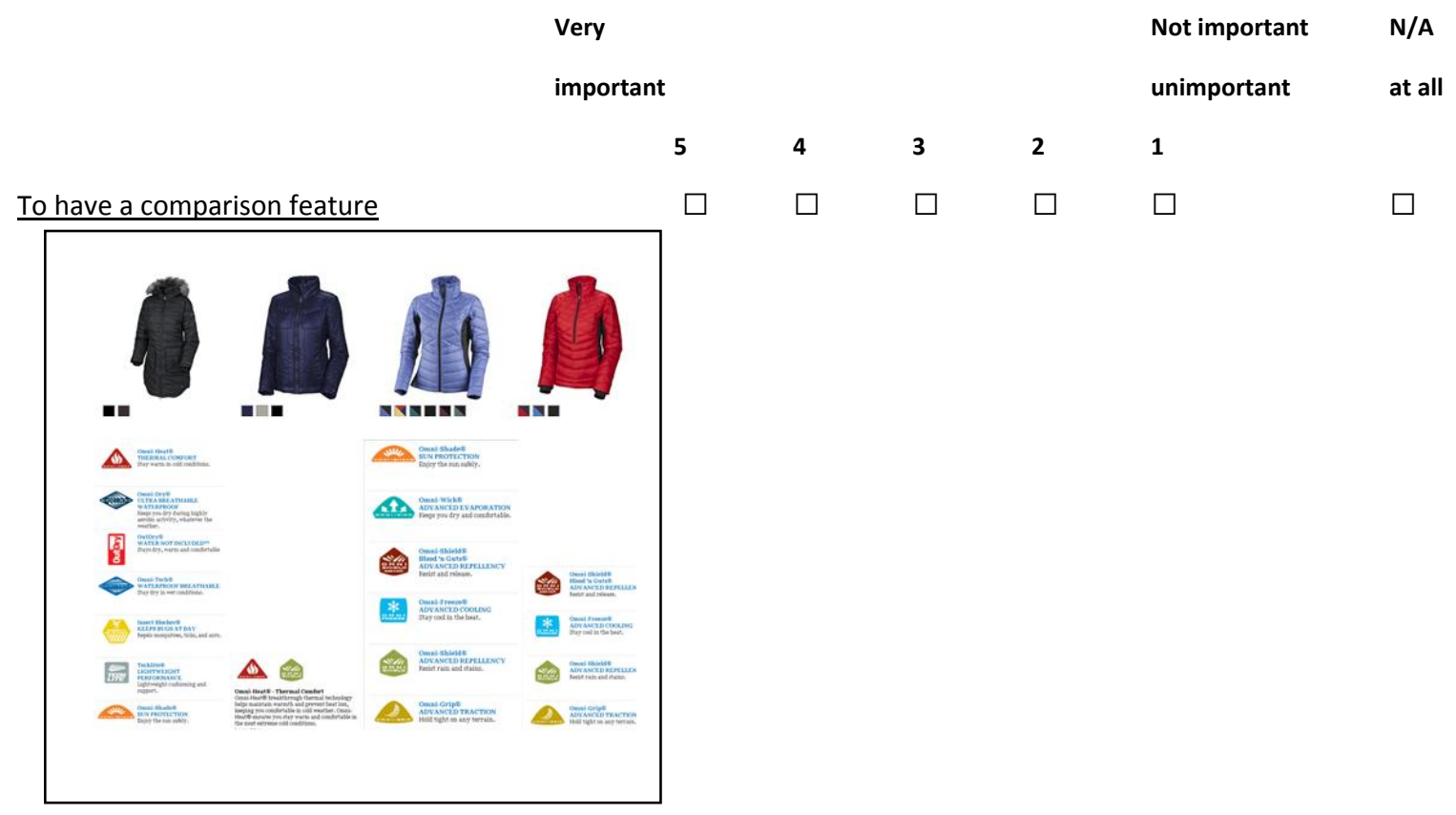

35. Thinking about the desired features that an apparel retailer's app could have, please indicate the importance of the following capabilities:

\begin{tabular}{|c|c|c|c|c|c|c|}
\hline & $\begin{array}{l}\text { Very } \\
\text { important }\end{array}$ & & & & $\begin{array}{l}\text { Not important } \\
\text { unimportant }\end{array}$ & $\begin{array}{l}\mathrm{N} / \mathrm{A} \\
\text { at all }\end{array}$ \\
\hline & 5 & 4 & 3 & 2 & 1 & \\
\hline To have a store locator feature & $\square$ & $\square$ & $\square$ & $\square$ & $\square$ & $\square$ \\
\hline
\end{tabular}

Find a Store Near You

Your Account

Wish List

36. Thinking about the desired features that an apparel retailer's app could have, please indicate the importance of the following capabilities:

$\begin{array}{llllll}\begin{array}{l}\text { Very } \\ \text { important }\end{array} & & & & \begin{array}{l}\text { Not important } \\ \text { unimportant }\end{array} & \begin{array}{l}\text { N/A } \\ \text { at all }\end{array} \\ 5 & 4 & 3 & 2 & 1 & \end{array}$

The ability to link to a video or image where I can see the product

$\underline{\text { In use or in a runway }}$ 

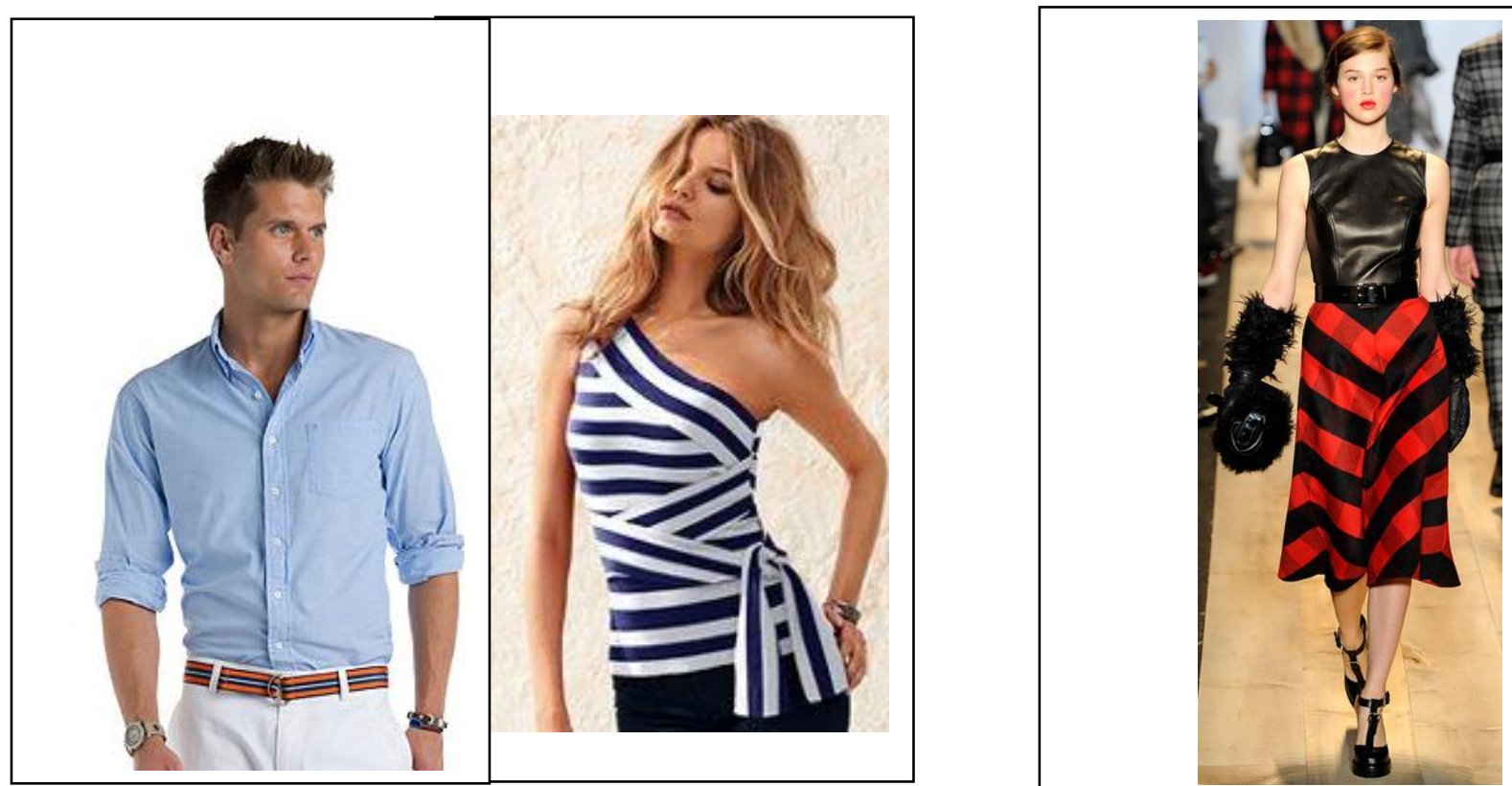

37. Do you usually sign-up to receive emails with communications and promotions from your apparel retailer?

$\square$ Yes

$\square$ No

38. How often do you like receiving those email communications?

Daily

2 or 3 times per week

$\square$ Once a week

$\square$ Twice a month

$\square$ Once a month

$\square$ Less than once a month

39. What would compel you to sign-up to receive email communications and promotions from your apparel retailer? Please check all that apply.

$\square$ A frequent shopper program to earn points and rewards redeemable for merchandise

$\square$ An immediate discount which I can apply to my first purchase

$\square$ To receive news and updates about new merchandise

To receive invitations for events that the retailer will be hosting

To receive discounts and promotions

To learn about new fashion trends

None of the above

Other

40. Do you usually sign-up to receive SMS (text) messages from your favorite apparel retailers?

$\square$ Yes 
$\square$ No

$\square$ I'm not familiar with SMS (text) messages

41. Which social networking sites do you usually visit? Please check all that apply.

$\square$ Facebook

$\square$ Linkedln

$\square$ Twitter

$\square$ Stumble Upon

DIGG

Foursquare

Pinterest

Instagram

Google +

Bright Kite

Reddit

Delicious

Other

$\square$ I don't visit any social networking sites/Not familiar

42. Are you familiar with the concept of "check-in" for social networking sites and apps?

$\square$ Yes, I have heard of it

$\square$ Yes, I have checked in

$\square$ No, and I'm not interested

$\square$ No, but l'd like to learn about them

43. Have you ever purchased something with your smartphone or tablet? Please check all that apply.

$\square$ An app

$\square$ Movie tickets

$\square$ A coffee

$\square$ Fast food

$\square$ A pizza

$\square$ Music

$\square$ No, I have not made purchases through my mobile device

$\square$ Other 
44. If you haven't made purchases with your mobile device, what are the reasons? (Please check all that apply).

$\square$ Intrusiveness/trust/privacy concerns/disclosure of personal information/security issues

$\square$ My phone can get stolen with my information

$\square$ At this point it is not as easy to make a purchase, perhaps in the future

$\square$ I'm not able to do a good research or shop around with the phone, it's too uncomfortable

I don't find it necessary

I prefer to have my products right away

\section{Shipping cost/inconvenience for returns}

I'm not sure how to shop from my mobile device/ Have not tried it

Other

45. If you have a credit card with a Paypass feature, have you ever "tapped" it to pay for something? Credit cards with the Paypass feature involve the use of Near Field Communication (NFC) technology in which the customer will pay by simply waving or tapping the credit card without the need for a pin or signature. For example: at selected McDonald's locations.
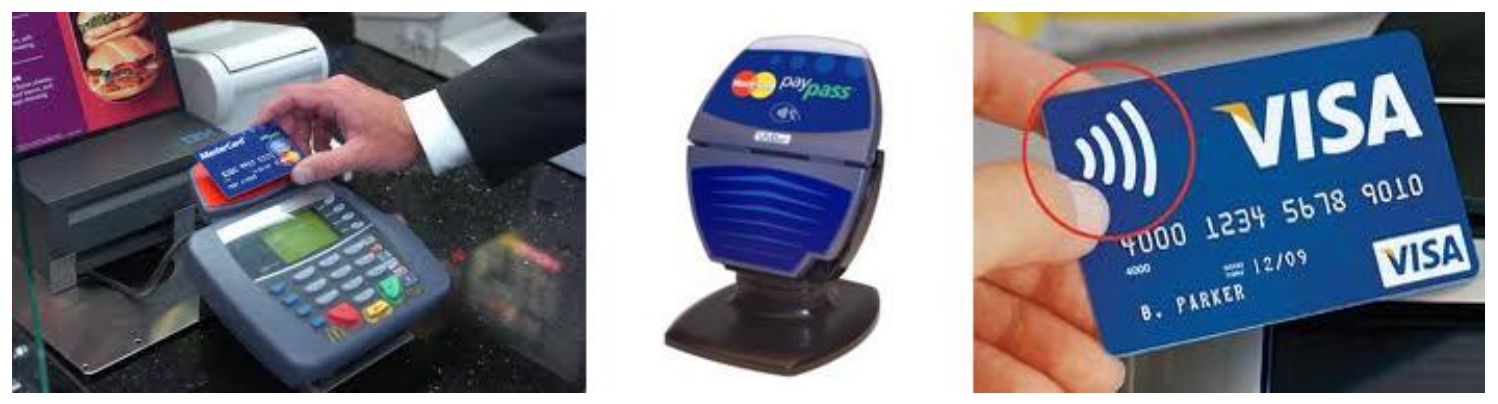

Yes, I have a credit card with a Paypass feature and have "tapped" it to pay

$\square$ Yes, I have a credit card with a Paypass feature but have never used this feature

No, my credit card doesn't have this feature

I'm not sure if my credit card has this feature

I don't have a credit card

46. Please indicate your gender.

Male

Female

Prefer not to answer

47. Please indicate your age group.

$18-24$ 
$\square$ 25-34

$\square$ 35-44

$\square$ 45-54

$\square 55$ and up

48. What is your annual household income?

$\square$ Less than 30,000

$\square 30,000-60,000$

$\square 60,000-90,000$

$\square 90,000-120,000$

$\square 120,000-150,000$

$\square 150,000$ or above

$\square$ Prefer not to answer

49. Please indicate your ethnic background.

$\square$ White/Caucasian

$\square$ Hispanic/Latin

$\square$ Asian/Oriental

$\square$ African-American/Black

$\square$ Arab/Middle Eastern

$\square$ Indian

$\square$ Mixed Race

$\square$ Other 


\section{Appendix C: Public Poster With Request for Research Participation}

\section{PARTICIPANTS NEEDED FOR RESEARCH}

You are invited to participate in a research study about Mobile Marketing for Apparel Retailers conducted by Ivonne Serna under the supervision of Prof. Osmud Rahman of Ryerson University. The study is for a Master's thesis.

If you decide to volunteer, you will be asked to complete a 20-30 minute online survey that is completed anonymously. Survey questions focus on usual use of your smartphone and about your apparel shopping preferences. Participation in this study is voluntary. You may decline to answer any questions that you do not wish to answer and you can withdraw your participation at any time, you may simply close your web browser and no data will be submitted. There are no known or anticipated risks from participating in this study.

It is important for you to know that any information that you provide will be anonymous. All of the data will be summarized and no individual could be identified from these summarized results. Furthermore, the web site is programmed to collect responses alone and will not collect any information that could potentially identify you (such as machine identifiers).

If you wish to participate, please visit the Study Website at https://survey.ryerson.ca/s?s=2270

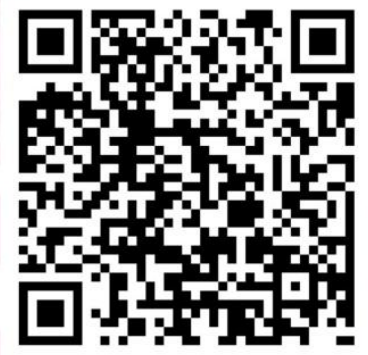

The data, with no personal identifiers, collected from this study will be maintained on a password-protected computer database in a restricted access area of the university. As well, the data will be electronically archived after completion of the study and maintained for three years and then erased.

Should you have any questions about the study, please contact either Ivonne Serna (Isernaze@ryerson.ca) or Osmud Rahman (orahman@ryerson.ca) Ph: 416-979-5000 x. 6911 or Ryerson University's Research Ethics Board at extensions 6300 or 7112.

I would like to assure you that this study has been reviewed and received ethics clearance through the Research Ethics Board at Ryerson University. However, the final decision about participation is yours. Thank you for considering participation in this study.

Please scan this QR code to answer the online survey
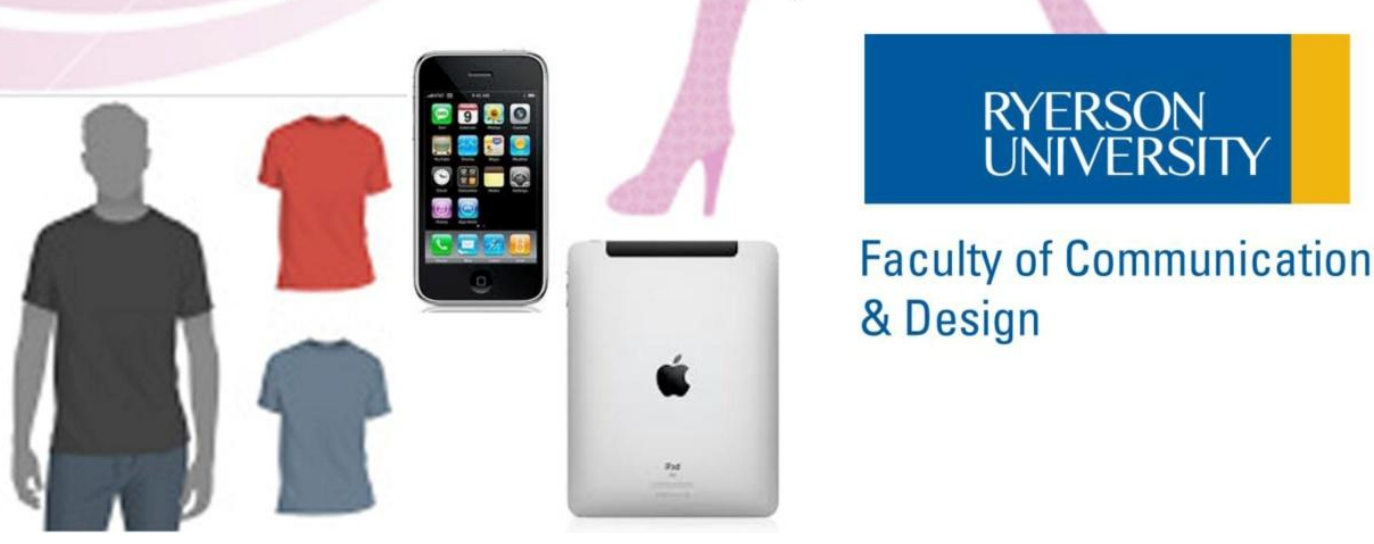


\title{
Appendix D: Research Ethics Board Approval
}

\section{RYERSON UNIVERSITY}

\author{
RESEARCH ETHICS BOARD
}

To: Leticia Ivonne Serna Zertuche

School of Fashion

Re: REB 2012-193: B2C (BUSINESS-TO-CONSUMER) MOBILE MARKETING FOR

CANADIAN APPAREL RETAILERS

Date: September 2, 2012

Dear Leticia Ivonne Serna Zertuche,

The review of your protocol REB File REB 2012-193 is now complete. The project has been approved for a one year period. Please note that before proceeding with your project, compliance with other required University approvals/certifications, institutional requirements, or governmental authorizations may be required.

This approval may be extended after one year upon request. Please be advised that if the project is not renewed, approval will expire and no more research involving humans may take place. If this is a funded project, access to research funds may also be affected.

Please note that REB approval policies require that you adhere strictly to the protocol as last reviewed by the REB and that any modifications must be approved by the Board before they can be implemented. Adverse or unexpected events must be reported to the REB as soon as possible with an indication from the Principal Investigator as to how, in the view of the Principal Investigator, these events affect the continuation of the protocol.

Finally, if research subjects are in the care of a health facility, at a school, or other institution or community organization, it is the responsibility of the Principal Investigator to ensure that the ethical guidelines and approvals of those facilities or institutions are obtained and filed with the REB prior to the initiation of any research.

Please quote your REB file number (REB 2012-193) on future correspondence.

Congratulations and best of luck in conducting your research.

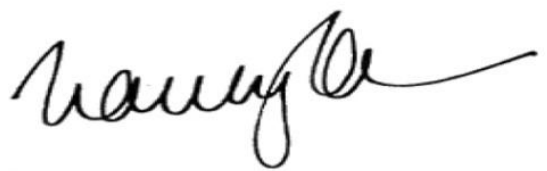

Nancy Walton, Ph.D.

Chair, Research Ethics Board 


\section{References}

Apple reports fourth quarter results. (2012, October 25). In Apple press info. Retrieved from http://www.apple.com/pr/library/2012/10/25Apple-Reports-Fourth-Quarter-Results.html

Arora, N., Dreze, X., Ghose, A., Hess, J., Iengar, R., \& Jing, B. (2008). Putting one-to-one marketing to work: Personalization, customization, and choice. Marketing Letters, 19, 305-321.

Bartlett, M. S. (1954). A note on the multiplying factor for various chi square approximations. Journal of the Royal Statistical Society, 16(Series B), 296-298.

Berkowitz, E. N., Walton, J. R., \& Walker, O. C. (1979). In home shoppers: The market for innovative distribution systems. Journal of Retailing, 55, 15-33.

Berners-Lee, T., Hendler, J., \& Lassila, O. (2001). The semantic web. Scientific American, 284(5), 34-43. doi:10.1038/scientificamerican0501-34

Bluetooth SIG Inc. (2012). Fast facts. Retrieved from http://www.bluetooth.com/Pages/FastFacts.aspx

Catell, R. B. (1966). The Scree test for number of factors. Multivariate Behavioral Research, 1, 245-276.

Çeltek, E. (2010). Mobile advergames in tourism marketing. Journal of Vacation Marketing, 16(4), 267-281.

Chasey, J. (2010). The evolution of mobile gaming. ITNOW, 52(6), 14-15.

Churchill, G. (1995). Marketing research methodological foundations. Fort Worth, TX: Dryden Press. 
Cisco. (n.d.). Physical access manager appliance user guide, release 1.1.0. Retrieved from http://www.cisco.com/en/US/docs/security/physical_security/access_control/cpam/1_1_0 /english/user_guide/glossary_cpam.html

Cisco. (2013, February 6). Visual networking index: Global mobile data traffic forecast update. Retrieved from http://www.cisco.com/en/US/solutions/collateral/ns341/ns525/ns537/ns705/ns827/white_ paper_c11-520862.html

Cockburn, C., \& Wilson, T. D. (1996). Business use of the World-Wide Web. International Journal of Information Management, 16(2), 83-102.

Dillman, D. A. (2007). Mail and Internet surveys: The tailored design method (2nd ed.). Hoboken, NJ: Wiley.

Ding, J. (2009). Advances in network management. Boca Raton, FL: CRC Press.

Farago, P. (2012, October 22). App engagement: The matrix reloaded [Web log post]. Retrieved from http://blog.flurry.com/bid/88867/iOS-and-Android-Adoption-ExplodesInternationally

Fayyad, U., Piatetsky-Shapiro, G., \& Smyth, P. (1996). Knowledge discovery and data mining: Towards a unifying framework. Proceedings of the second international conference on knowledge discovery and data mining. Retrieved from http://citeseerx.ist.psu.edu/viewdoc/summary?doi=10.1.1.27.363

Feijoo, C., Gómez-Barroso, J. L., Aguado, J. M., \& Ramos, S. (2012). Mobile gaming: Industry challenges and policy implications. Telecommunications Policy, 36(3), 212-221.

Fink, A., Bourque, L. B., \& Fielder, E. P. (2003). The survey kit: How to conduct selfadministered and mail surveys (2nd ed.). Thousand Oaks, CA: Sage. 
Geier, E. (2007). Wi-Fi hotspots: Setting up public wireless Internet access. Indianapolis, IN: Cisco Press.

Gidofalvi, G., \& Larsen, H. R. (2008). Estimating the capacity of the location-based advertising channel. International Journal of Mobile Communications, 6(3), 357-375.

Gillenson, M. L., Sherrell, D. L., \& Chen, L. (1999). Information technology as the enabler of one-to-one marketing. Communications of the AIS, 2(3).

Google and Facebook top 2011's most visited sites in US. (2011, December 29). BBC News, p. Retrieved from http://www.bbc.co.uk/news/technology-16356066.

Ha, S., \& Stoel, L. (2009). Consumer e-shopping acceptance: Antecedents in a technology acceptance model. Journal of Business Research, 62(5), 565-571.

Hahn, K. H., \& Kim, J. (2004. The effect of offline brand trust and perceived Internet confidence on online shopping intention in the integrated multi-channel context. International Journal of Retail \& Distribution Management, 39(2), 126-141.

Hansen A. H., \& GrØnbæk, K. (2011). Urbanweb: A platform for mobile, context-aware web services. In S. A. Ahson \& M. Ilyas (Eds.), Mobile Web 2.0: Developing and delivering services to mobile devices (pp.137-161). Boca Raton. FL: Auerbach.

Hoffman, L., \& Novak, T. P. (1997). A new marketing paradigm for electronic commerce. The Information Society, 13, 43-54.

IBM. (2012). IBM 2012 holiday benchmark reports: Black Friday [Data file]. Retrieved from http://www-01.ibm.com/software/marketing-solutions/benchmark-reports/black-friday2012.html

Jackson, S. L. (2009). Research methods and statistics: A critical thinking approach (3rd ed). Belmont, CA: Wadsworth. 
Jones, J. M., \& Vijayasarathy, L. R. (1998). Internet consumer catalog shopping: Findings from an exploratory survey and directions for future research. Internet Research, 8(4), 322-330.

Junglas, I., \& Watson, R. (2008). Location based services: Evaluating user perceptions of location-tracking and location awareness services. Communications of the ACM, 51(3), 65-69.

Kaiser, H. (1974). An index of factorial simplicity. Psychometrika, 39, 31-36.

Kammer, D., McNutt, G., Senese, B., \& Bray, J. (2002). Bluetooth application developer's guide: The short range interconnect solution. Rockland, MA: Syngress.

Kang, J., \& Park-Poaps, H. (2010). Hedonic and utilitarian shopping motivations of fashion leadership, Journal of Fashion Marketing and Management, 14(2), 312-328.

Karmali, L. (2012, October 4). Mists of Pandaria pushes Warcraft subs over 10 Million. IGN Entertainment. [Web log post]. Retrieved from http://ca.ign.com/articles/2012/10/04/mists-of-pandaria-pushes-warcraft-subs-over-10million

Kato, H., Keng, T., \& Chai, D. (2010). Barcodes for mobile devices. Cambridge, UK: Cambridge University Press.

Kaufman-Scarborough, C., Morrin, M., \& Bradlow, E. T. (2010). Improving the crystal ball: Harnessing consumer input to create retail prediction markets. Journal of Research in Interactive Marketing, 4(1), 30-45.

Khalaf, S. (2012, December 5). Mobile apps: We interrupt this broadcast [Web log post]. Retrieved from http://blog.flurry.com/bid/92105/Mobile-Apps-We-Interrupt-ThisBroadcast 
Krum, C. (2010). Mobile marketing: Finding your customers no matter where they are. Indianapolis, IN: Que.

Kukar-Kinney, M., Ridgway, N., \& Monroe, K. (2012). The role of price in the behavior and purchase decisions of compulsive buyers. Journal of Retailing, 88(1), 63-71.

Kumar, V., \& Reinartz, J. (2006). Customer relationship management: A database approach. Hoboken, NJ: Wiley.

Laughlin, D. (2012, December 13). The gamification of mobile games [Web log post]. Retrieved from http://blog.flurry.com/bid/92377/The-Gamification-of-Mobile-Games

Lee, Y. J., \& Radosevich, D. (2012). Exploring mobile app market strategies: Free app versus paid app. International Journal of Strategic Management, 12(4), 97.

Lomas, N. (2013, February 12). Amex launches pay by tweet, turns purchases into adverts [Web log post]. Retrieved from http://techcrunch.com/2013/02/12/amex-pay-by-tweet/

Luedi, A. F. (1997). Personalize or rerish. Electronic Markets, 7(3), 22-25.

Lunden, I. (2012, September 24). Facebook mobile payments via carrier billing (and bango) live In U.S., UK and Germany [Web log post]. Retrieved from http://techcrunch.com/2012/09/24/facebook-mobile-payments-via-carrier-billing-andbango-now-live-in-u-s-uk-and-germany/

MacMillan, D. (2010). Zynga and Facebook. It's complicated. Business Week, 4176, 47. Retrieved from http://www.businessweek.com/stories/2010-04-21/zynga-and-facebookdot-its-complicated

Malhotra, N. K. (2007). Marketing research: An applied orientation. New York, NY: Prentice Hall. 
Martin, C. (2011). The third screen: Marketing to your customers in a world gone mobile.

Boston, MA: Nicholas Breasley.

McDaniel, C., \& Gates, R. (1999). Contemporary marketing research. Cincinnati, OH: SouthWestern College Publishing.

Mishra, A. (2010). Cellular technologies for emerging markets: $2 G, 3 G$ and beyond. West Sussex, UK: Wiley.

Mobile Marketing Association. (2008). Mobile marketing industry glossary. Retrieved from http://mmaglobal.com/uploads/glossary.pdf

Mohammadi, E. (2011). Indoor location based services (Master's thesis). University of Alberta, Calgary, Alberta. Retrieved from http://tinyurl.com/c8o6nku

Murthy, V. K. (2004). Contract-based workflow design patterns in M-commerce. In N. Si Shi (Ed.), Mobile commerce applications (p. 25). Hershey, PA: Idea Group.

Nayak, R., \& Seow, L. (2004). Knowledge discovery in mobile business data. In N. Si Shi (Ed.), Mobile commerce applications (p. 117). Hershey, PA: Idea Group.

Office of the Privacy Commissioner of Canada. (2011, December 6). New online advertising guidance sets out restrictions for tracking. Retrieved from http://www.priv.gc.ca/media/nr-c/2011/nr-c_111206_e.asp

Peppers, D., \& Rogers, M. (1993). The one to one future: Building relationships one customer at a time. New York, NY: Currency/Doubleday.

Pookulangara, S., Hawley, J., \& Xiao, G., (2010). Explaining multi-channel consumers channelmigration intention using theory of reasoned action. International Journal of Retail \& Distribution Management, 39(3), 183-202. 
Rahman, O. (2011). Understanding consumers' perceptions and behaviour: Implications for denim jeans design. Journal of Textile and Apparel, Technology and Management, 7(1), 1-16. Retrieved from http://ojs.cnr.ncsu.edu/index.php/JTATM/article/viewFile/845/909

Rahman, O., Zhu, X., Liu W-S. (2008). A study of the pyjamas purchasing behaviour of Chinese consumers in Hangzhou, China. Journal of Fashion Marketing and Management, 12(2), $217-231$.

Rangaswamy, A., \& Van Bruggen, G. H. (2005). Opportunities and challenges in multi-channel marketing: An introduction to the special issue. Journal of Interactive Marketing, 19(2), 5-11.

Rappaport, T. (2002). Wireless communications: Principles and practices. Upper Saddle River, NJ: Prentice Hall.

Rogers, E. M. (1995). Diffusion of innovations (4th ed.). New York, NY: The Free Press.

Schmidt, E. (2012). There will be an Android in every pocket. Mobile World Live Barcelona 2012. Retrieved from http://www.mobileworldlive.com/videos/google-there-will-be-anandroid-in-every-pocket/22677

Shi, H. (2004). An empirical study on predicting user acceptance of e-shopping on the Web. Information \& Management, 41(3), 351-368.

Shim, S., \& Drake, M. F. (1990). Consumer intention to purchase apparel by mail order: Beliefs, attitude, and decision process variables. Clothing and Textiles Research Journal, 9(1), $18-26$.

Siegler, M. (2013, February 14). The fall TV lineup may include Apple dominating gaming. [Web log post]. Retrieved from http://techcrunch.com/2013/02/14/death-by-apps/ Skeldon, P. (2011). mCommerce: Boost your business with the power of mobile commerce. Surrey, UK: Crimson Publishing. 
Smith, A., Segall, L., \& Cowley, S. (2012, October 4). Facebook reaches one billion users. CNN Money. Retrieved from http://money.cnn.com/2012/10/04/technology/facebook-billionusers/index.html

Stoutenbourgh, J. W. (2008). Demographic measures. In P. J. Lavrakas (Ed.), Encyclopedia of survey research methods (Vol. 1, pp. 185-186). Thousand Oaks, CA: Sage.

Swaminathan, V., Lepkowska-White, E., \& Rao, B. P. (1999). Browsers or buyers in cyberspace? An investigation of factors influencing electronic exchange. Journal of Computer-Mediated Communication, 5(2), 1-19.

United States Bureau of Labor Statistics. (2011). American time use survey: 2011 results [Data file]. Retrieved from http://www.bls.gov/news.release/pdf/atus.pdf

Varshney, U. (2001). Location management support for mobile commerce applications. In Proceedings of the First International Workshop on Mobile Commerce (pp.1-6).

Weltevrenden, J. W., \& Boschma, R. A. (2008). Internet strategies and the performance of Dutch retailers. Journal of Retailing and Consumer Services, 15, 163-178.

Whitley, B. E. (1996). Principles of research in behavioral research (2nd ed.). New York, NY: McGraw-Hill.

Wisely, D. (2009). IP for 4G. West Sussex, UK: Wiley.

Wirtz, B.W., Schilke, O., \& Ullrich, S. (2010). Strategic development of business models: Implications of the Web 2.0 for creating value on the Internet. Long Range Planning, 43(2/3), 272-290.

Yang, H. L., \& Wang, C. H. (2008). Product placement of computer games in cyberspace. Cyberpsychology \& behavior: The impact of the Internet, multimedia and virtual reality on behavior and society, 11(4), 399-404 